University of Rhode Island

DigitalCommons@URI

Open Access Master's Theses

1991

\title{
BACK TO THE FUTURE: ZONING ALTERNATIVES IN THE SUBURBS
}

Daniel E. Clement

University of Rhode Island

Follow this and additional works at: https://digitalcommons.uri.edu/theses

\section{Recommended Citation}

Clement, Daniel E., "BACK TO THE FUTURE: ZONING ALTERNATIVES IN THE SUBURBS" (1991). Open Access Master's Theses. Paper 554.

https://digitalcommons.uri.edu/theses/554

This Thesis is brought to you for free and open access by DigitalCommons@URI. It has been accepted for inclusion in Open Access Master's Theses by an authorized administrator of DigitalCommons@URI. For more information, please contact digitalcommons-group@uri.edu. 
BACK TO THE FUTURE:

ZONING ALTERNATIVES IN THE SUBURBS

BY

DANIEL E. CLEMENT

\begin{abstract}
A RESEARCH PROJECT SUBMITTED IN
PARTIAL FULFILLMENT OF THE REQUIREMENTS

FOR THE DEGREE AND MASTER OF

COMMUNITY PLANNING
\end{abstract}

UNIVERSITY OF RHODE ISLAND

1991 


\section{MASTER OF COMMUNITY PLANNING \\ RESEARCH PROJECT \\ OF}

DANIEL E. CLEMENT

Approved :

Major Professor

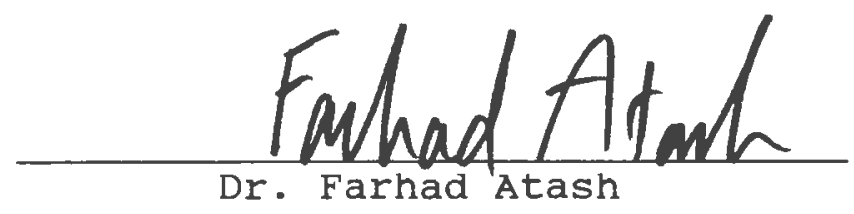

Acknowledged:

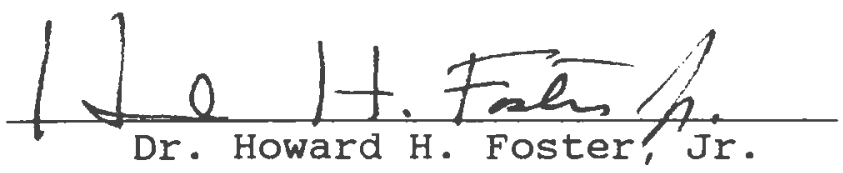




\section{A C K K N O W L E D G E M E N T S}

This study was first conceived of during a conference I attended in washington, D.C. in september of 1990. The development of that initial idea to the final document presented here would not have been possible without the guidance and assistance of several people.

I would like to thank both Dr. Farhad Atash and Richard Youngken for the time they both spent discussing the pros and cons of the concepts and design principles talked about in this study. During the course of this study I was able to bounce ideas off of them whenever I needed to. Their comments were always helpful to me.

I also want to acknowledge many of my classmates for the time they spent listening to me proselytize about this stuff. It did not go unnoticed. Their thoughts and their comments were greatly appreciated. 
$\begin{array}{llllllllllllll}\text { T A B L E } & \text { O F } & \text { C O } & \text { N } & \text { T } & \text { E } & \text { N } & T & S\end{array}$

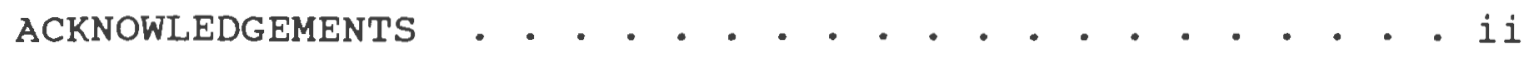

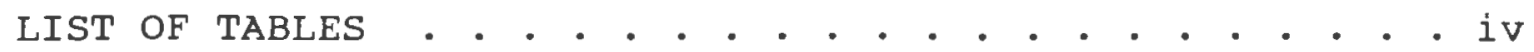

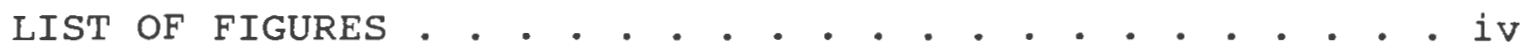

CHAPTER ONE

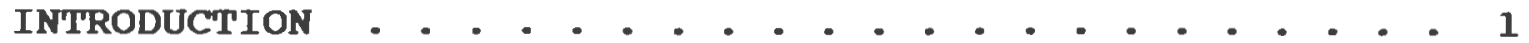

CHAPTER TWO

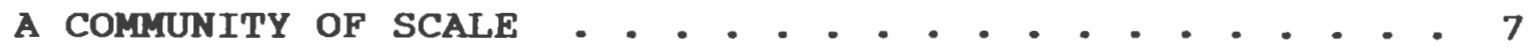

INTRODUCTION •. . . . . . . . . . . . . . . . . . . 7

THE SEARCH FOR HUMAN SCALE . . . . . . . . . . 12

CONCLUSIONS . . . . . . . . . . . . . . . . . . 22

CHAPTER THREE

THE NEED FOR ALTERNATIVES . . . . . . . . . . . . . . . . 24

INTRODUCTION . . . . . . . . . . . . . . . . . . . . 24

THE EVOLUTION OF SEGREGATED ZONING • • • • • • • . . 25

ZONING IN THE URBAN CORE . . . . . . . . . . . . 27

ZONING OUTSIDE THE URBAN CORE . . . . . . . . . . . 33

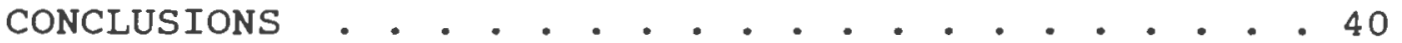

CHAPTER FOUR

NEW TRENDS IN SUBURBAN PLANNING AND DESIGN • . • . . . . 42

INTRODUCTION . . . . . . . . . . . . . . . . . . 42

PERFORMANCE ZONING . . . . . . . . . . . . . . . . 42

NEOTRADITIONAL TOWN PLANNING . . . . . . . . . . 50

PEDESTRIAN POCKETS . . . . . . . . . . . . . . 62

RURAL LANDSCAPE PLANNING . . . . . . . . . . . 68

CONCLUSIONS • . . . . . . . . . . . . . . . . 70

CHAPTER FIVE

MAKING THE NEW TRENDS APPLICABLE INTRODUCTION . . . . . . . . . . . . . . . . . 71 PRESENTING THE ALTERNATIVES . . . . . . . . . . 75 THE ALTERNATIVES APPLIED . . . . . . . . . . . . 80

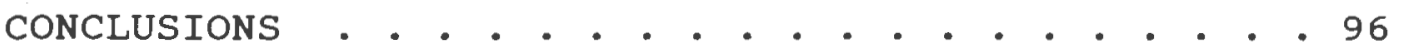

REFERENCES 
Table 4.1 - Performance Zoning Districts . . . . . . . . 46

Table 4.2 - Planning and Design Characteristics in Hamlets and Villages . . . . . . . . 60

Table 4.3 - Community Facilities and Services in Hamlets and Villages . . . . . . . . . 61

Table 4.4 - Typical Requirements for a Pedestrian Pocket .. . . . . . . . 65

\section{$\begin{array}{lllllllllll} & I & S & T & O & F & F & I & G & R & \end{array}$}

Figure 2.1 - Savannah, Georgia . . . . . . . . . . 9 a.) Perspective View (c.1734)

b.) Savannah, Georgia. Neighborhood Unit

Figure 2.2 - Lowell, Massachusetts . . . . . . . . . . 11

Figure 2.3 - North Uxbridge, Massachusetts . . . . . . 11

Figure 2.4 - Garden City . . . . . . . . . . . . . 15

Figure 2.5 - Regional Plan for Garden Cities . . . . . 15

Figure 2.6 - Clarence Perry's Neighborhood Unit . . . . 18

Figure 2.7 - Neighborhood Unit (c. 1939) . . . . . . . 18

Figure 2.8 - Radburn, New Jersey . . . . . . . . . . 21

a.) Neighborhood Unit

b.) Master Plan

Figure 3.1 - Subdivision Design Standards (c. 1939) . . 30

a.) Suggested Road layout

b.) Standards for Roads and Lots

Figure 3.2 - Overlook Colony, Delaware . . . . . . . . 31

Figure 4.1 - Performance Zoning Housing Types . . . . . 49

Figure 4.2 - TND Ordinance . . . . . . . . . . . . . . . 52

Figure 4.3 - Seaside, Florida . . . . . . . . . . . 53

Figure 4.4 - Deerfield TND in Merriville, Indiana . . . 54

Figure 4.5 - Pedestrian Pocket . . . . . . . . . . 64

Figure 5.1 - Foster, Rhode Island Zoning . . . . . . . 84

Figure 5.2 - Foster, Rhode Island Performance Zoning . . 92 


\section{PROBLEM STATEMENT}

More and more small and mid-sized communities are grappling with the problems associated with sprawl patterns of development. In most cases, these patterns are the result of a long standing practice in the planning profession toward the segregation of large areas of land into separate zones for home (residential), work (industrial) and market (commercial). This practice has led to the creation of a suburban pattern based on the physical application of this segregation in the form of the subdivision (residential), industrial or office park (industrial) and the strip center or shopping mall (commercial). It is a pattern of development that carries with it, the wholesale destruction of the natural landscape and a heavy dependence on the automobile as the chief mode of transit.

Many communities chose to combat the problem by increasing necessary lot sizes and reducing the size of allowable commercial and industrial uses. These tactics did not solve the problem. It just reduced the density of the sprawl and created a host of new problems. Larger lots consumed more land for private use. Affordable housing disappeared as larger homes were constructed on larger lots. A second (and in some cases even a third) family car was 
needed for commuting between both the workplace and the market place. The increase in automobile traffic increased both travel distances and times in many communities.

Several recent trends in both urban and suburban design have dealt directly with the problems created with segregated land uses and sprawl patterns of development - most notably Neotraditional Town Planning, Performance Zoning, and Rural Landscape Planning. While each design solution has features that make them unique, there are several common themes running through all of them; decreasing the segregation of uses through mixed use design concepts, increasing the variety and amount of shared common or open space, and decreasing the reliance on the automobile.

\section{OBJECTIVE}

There exists a need for additional study of these concepts in a more comprehensive manner and in a way that takes into account existing land use patterns. The objective of this study is to incorporate recent trends in planning in an effort to demonstrate their effectiveness in curtailing the sprawl patterns of development caused by conventional zoning. The current land use and zoning policies of Foster, Rhode Island will be used as a model for comparison. The purpose is to let planners and public officials know that there are viable alternatives to the forms of conventional zoning that have been in use for the last 75 years. 


\section{NEED FOR THE STUDY}

There is an ever increasing feeling among decision makers and professionals that there are limited alternatives available in planning for small communities on the urban fringe. In most cases these alternatives involve slowing growth and lowering density. Any solution that proposes to do the opposite is confronted by the angry cry of "Not In My Back Yard" by local residents and branded as locally undesirable land uses (LULU's). Unfortunately, many of the more recent trends do trade off higher or more concentrated densities in one area with the benefits of increasing open or common space in another. It is because these solutions are so radically different from the standard patterns of development that they appear to be so menacing to many.

Yet, these new trends have at their base a firm ground on historic settlement patterns that predate the existing land use patterns created by conventional zoning. They are based on the sense of community and commonality that can exist in a smaller more densely settled community core. By demonstrating how these settlement patterns can work and familiarizing the public with what can be achieved through their development, planners and decision makers can increase the number of land use alternatives available in determining the long range planning needs of the community. 


\section{RELATED LITERATURE}

Literature related to the study can be divided into three categories; historic or background materials on settlement patterns, guidelines on planning that follow the existing segregated patterns of land use, and theoretical materials and case studies that demonstrate the recent trends in community planning and design.

Historical or background material will be used to show that what is being advocated by many planners today is not new and radically different but is, in actuality, a return to a more desirable pattern of land use that existed prior to the post World War II suburban migration. This section will focus on many of the historic concepts of community and neighborhood that were advocated by social reformers in the late nineteenth and early twentieth century. Of particular importance will be the development of New Town Planning and the neighborhood unit. These concepts have been routinely cited by advocates of these new trends in planning.

Guidelines that promote patterns of segregated land use will be analyzed to determine what role they have played in the growth of the sprawl community. This type of literature includes current examples of zoning ordinances and subdivision regulations and both historic and current design manuals that use methods of development - such as segregated uses and hierarchical street patterns - that have perpetuated sprawl 
pattern development. This type of literature has promoted these principles as being the only correct way to zone.

The third section will use literature available on recent trends - Performance Zoning, Neotraditional Planning, Pedestrian Pockets and Rural Landscape Planning. Most of this information comes in the form of published articles in magazines an trade journals. Other sources of literature come from recent workshops and lectures for professional designers and planners. This literature will be compared with existing guidelines on segregated land use planning in order evaluate how new trends can be incorporated into the existing fabric and land use policies of a community.

\section{ORGANIZATION OF THE STUDY}

The study is divided into four sections. The first section (Chapter 2) looks at the question of community scale. Most of the problems with sprawl pattern development stem from the lack of scale in fringe community. This section will explore the idea that there was a strong move toward limiting the scale of the built environment in the early development of planning in the first town decades of this century.

The second section (Chapter 3) looks at the cause and effect of conventional zoning. It examines the development of conventional zoning as a way to stem problems caused by rapid urbanization in the late 19th century. The section then focuses on the application of conventional zoning in areas 
outside the urban core. For the purposes of this study communities outside the core has been labeled fringe communities. The definition of a fringe community is a community which still has a large majority of its available land undeveloped. Fringe communities have usually taken steps to preserve this undeveloped land by rezoning land for very low density residential uses.

The third section (Chapter 4) will outline new trends in suburban and rural planning and design. The fundamental concepts and design guidelines of each alternative will be presented so that the reader see how these new trends compare with early concepts in planning and current methods of conventional zoning. This chapter will also focus on the similarities between the current alternatives and how they can be integrated to form the fundamental basis for a new method of zoning.

The final section (Chapter 5) will show how the alternative techniques in Chapter 4 have been presented to communities by the planners who promote them. The alternatives will then be used in the Town of Foster to suggest how one community can break out of the conventional zoning trap. Existing land use and zoning will be examined to determine the impacts caused by conventional zoning. Community goals and objectives will be analyzed using recent data prepared for the comprehensive plan update and alternatives will be suggested that are in keeping with these goals and objectives. 
A Comminity of Scale

\section{INTRODUCTION}

The search for the ideal community - one that achieves a harmonious balance of places to live and work - is the ultimate goal of planning. In achieving that goal, there always seems to be a search for the right formula that could be used to achieve the correct size and shape of this ideal Community. At times of great change this search intensifies. Whether it was during the rise of the Renaissance, the period following the discovery of the new world, or the onset of the Industrial Revolution, there always seems to be a call for a new order to the built environment.

Today, is no different. The rapid suburbanization of the last 50 years has brought great change. The dominance of the urban center has been diminished and the rise of the suburban center continues to grow. Critics establish that the rigid segregation of uses practiced in the suburbs has perpetuated a form of growth that is unhealthy and must be corrected. But has it?

To some extent, man has always separated himself from his work. The farmer did not sleep in his field. The shopkeeper did not live in his shop. They may have Iived adjacent to or above where they worked but they almost always segregated where they worked from where they lived. In an age of limited 
travel it was practical for home and residence to be in close proximity. This relationship formed the basis for settlement patterns in America.

This idea of natural segregation of uses found its way into the settlement patterns of America. Why else would we have a "Main Street"? The rise of the colonial city - long before zoning - practiced a more subtle form of land use segregation. As property values along Main street became more valuable and the street itself became more congested, the residential uses above and adjacent were either forced out or moved to the more peaceful surroundings found further out. Waterfront and warehouse districts grew naturally to meet the needs of the new commercial districts adding to the outmigration from the town center.

Even in the "planned" communities of colonial America there was a segregation of uses in the design. The city of Savannah, Georgia laid out by James Oglethorpe used a grid design with public and private lots surrounding open squares. (Figure 2.1) The basic unit contained house lots to the north and south and public lots to be used for stores and churches. As the city grew economic forces shaped the development around some squares to predominantly commercial use while others have stayed predominantly residential.

In williamsburg, Virginia another "planned community" of the 17th century, a more formal axial arrangement of house lots and public spaces was laid out. It was originally 
Figure 2.1 - Savannah, Georgia

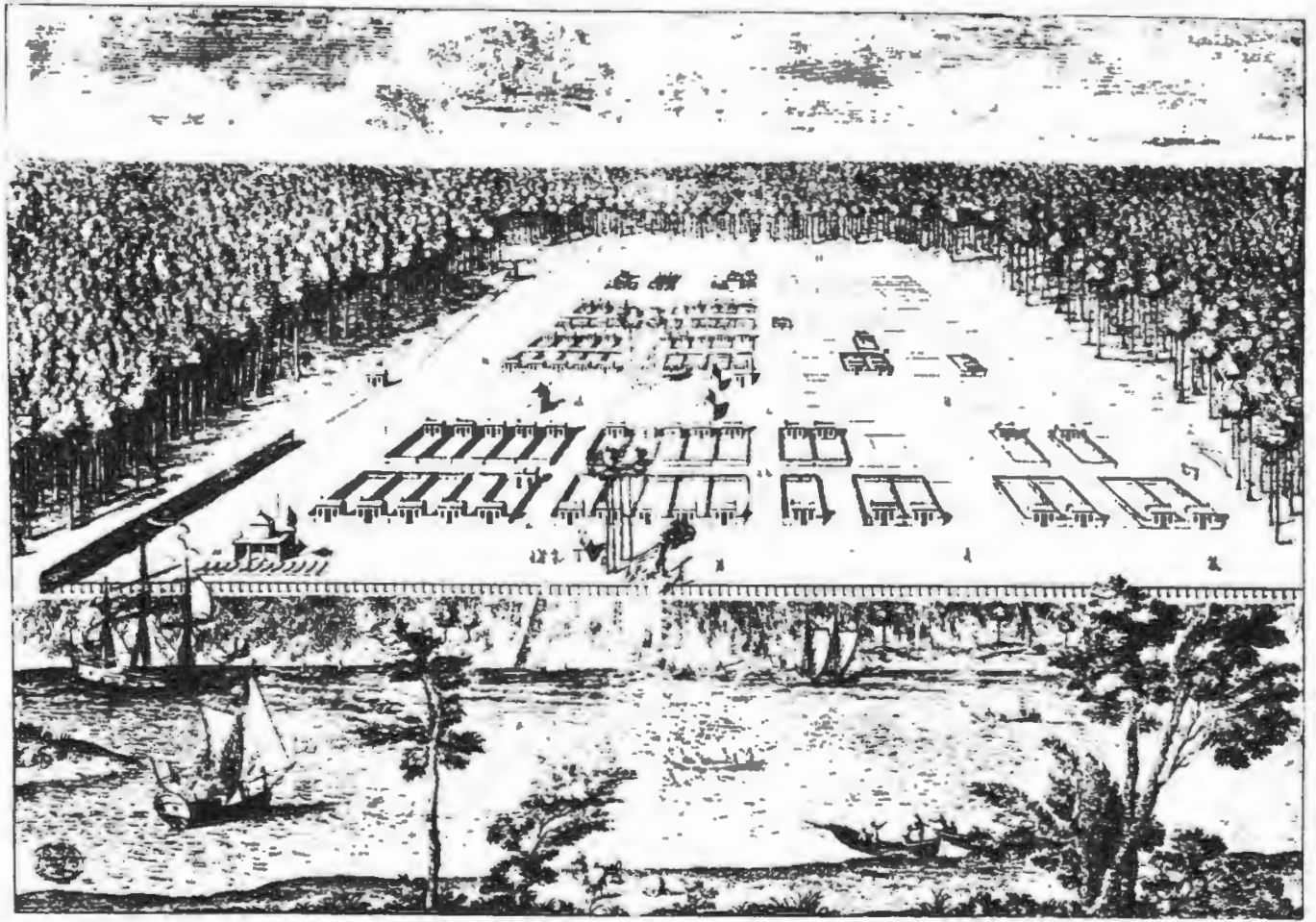

a.) Perspective drawing of Savannah, c.1734.

The plan of Savannah shows the use of the modified grid pattern using public lots $(W, X, Y, Z)$ in b) surrounding open space. Tything lots are individual house lots and were large enough to allow the raising of crops and the keeping of livestock. This is a very early example of a neighborhood unit. As seen in a) the ability to continually extend a grid system is why it was used so extensively.

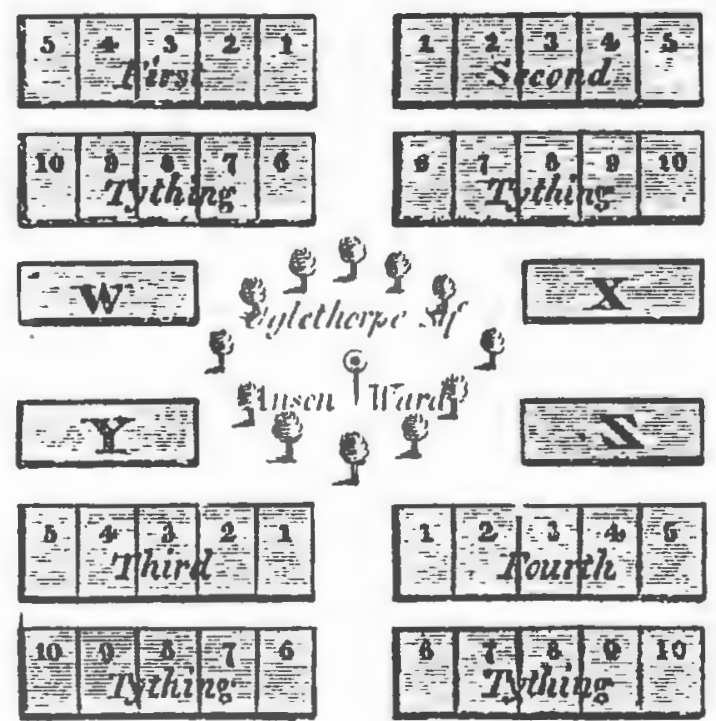

Source: America By Design, 1987. 
designed as Virginia's state Capitol but never grew to be a large city. Restoration underway since the early 20 th century affords the visitor a unique perspective of how a mix of residential and commercial uses were informally separated in small settlements. Even though shopkeepers and businessmen practiced their trades under one roof, architectural design was still used to segregate the uses. Shops were built with separate entrances, as separate wings of the structure, or even as outbuildings on the same property.

The mill towns of the late 18 th and early 19 th century practiced a more rigid notion of segregation. The mill was located in the most practical place (usually on the river). Housing for mill workers while located nearby was still separated from the mill area. This clear segregation of use can be seen in the plans for mill towns like Lowell, North Uxbridge in Massachusetts. (Figures $2.2 \& 2.3$ )

If man has a natural tendency to segregate uses what is the problem? Practically every community in America has zones for residential, commercial and industrial uses. The residential zones tend to be adjacent to commercial zones and industrial zones are located somewhere within the town line. What's the problem?

The problem stems not from the segregation itself. It has more to do with the scale of the segregation. Sprawl is not a problem caused by segregation but by the scale of segregation. When the proponents of these new trends in 
Figure 2.2 - Lowe11, Massachusetts

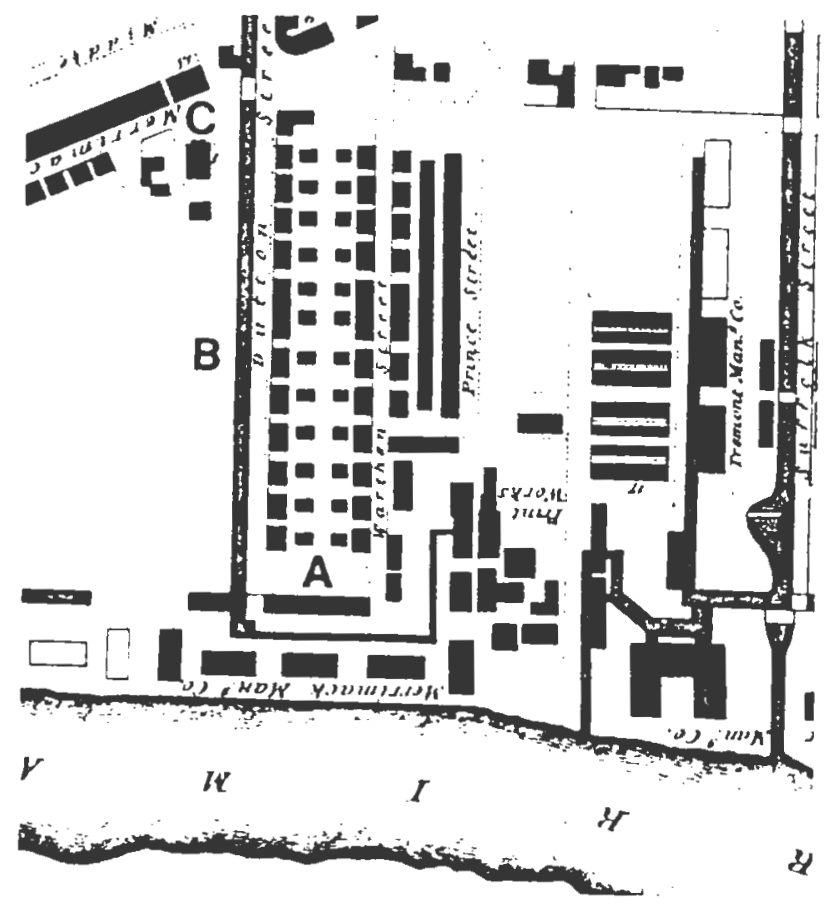

Lowell was perhaps one of the most progressive mill towns of the early Industrial Revolution. This plan shows the relationship between the mills and housing supplied for the workers. The relatively clean use of water power to run the mills allowed the housing to be built adjacent to the mills. The long blocks along prince street commercial shops.

Source: American Buildings and Their Architects, 1980

Figure 2.3 - North Uxbridge, Massachusetts

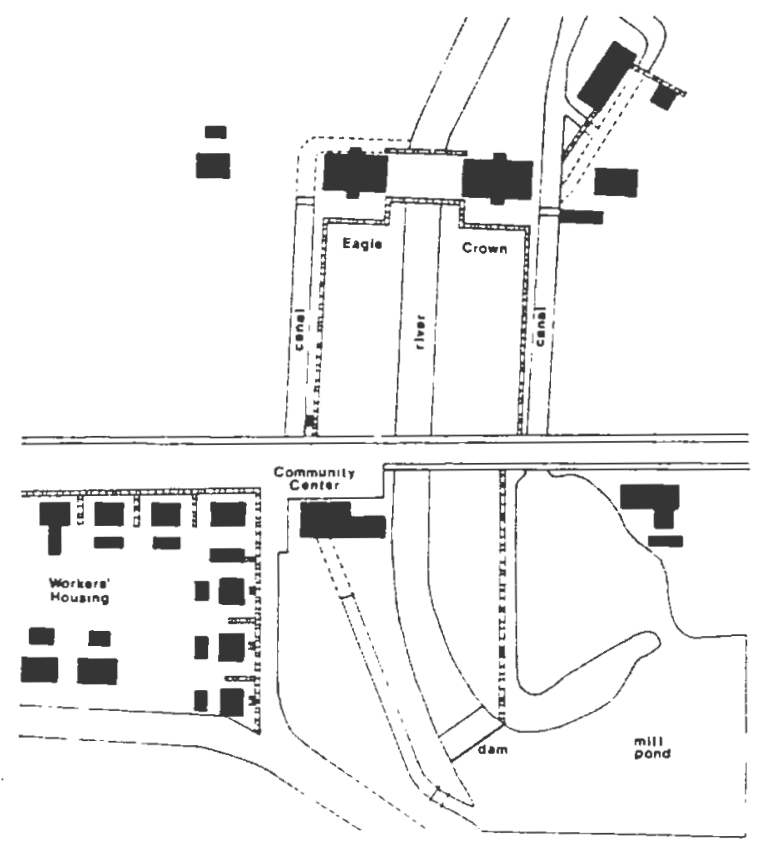

The segregation of workers housing is again seen in this map showing the grounds of the crown and Eagle mills in North Uxbridge. Notice the Community center located along the river and adjacent to the worker's housing.

Source: American Buildings and Their Architects, 1980. 
planning are talking about mixed uses, open space and pedestrian accessibility they are really talking about scale. A scale that is more human and therefore more manageable. When communities are designed with human scale in mind then segregation of use is not a major problem.

\section{THE SEARCH FOR HUMAN SCALE}

There was no greater loss in human-scaled settlement patterns in America than that which occurred during the late 19th and early 20th centuries. The conditions caused by industrialization and urbanization created a need for rediscovering a more manageable form of settlement pattern. This section will examine how social reformers took different approaches in looking for the ideal proportions for creating a more human environment than could be found in the existing urban fabric. one group determined the only way was to abandon the unnatural growth in the urban city and start fresh on the outskirts with the new town or garden city. A second group sought to change the existing urban environment from within. They would mold the city into their image with series of compact self-sufficient neighborhood units.

\section{The New Town Ideal}

"New Towns are planned communities consciously created in response to clearly stated objectives".(Galantay, 1975) The concept was to combine several neighborhoods, each with their 
own neighborhood center, around a larger town center that would serve the needs of all the neighborhoods. This definition describes many of the cities and towns mentioned in the previous section. This section will focus on the period of new town development during the early 20th century. The development of new town concepts during this period was reactionary and sought to change the nature of settlement patterns that had developed over the last half century.

Several industrialists had already moved their factories out of the cities to create company towns on the assumption that happy workers are productive workers. While not exactly noble these industrialists did recognize the debilitating aspects that were created in the densely populated urban center. The company towns were fairly compact and like the early mill towns rigidly segregated worker housing from the factory areas.

The real push for new towns as the means for complete social reform was provided by the publication of Garden cities of Tomorrow by Ebenezer Howard in London in $1898 .^{1}$ The book promoted the decentralization of the urban center with the establishment of new towns with populations of approximately 30,000 residents, and separated by broad expanses of undeveloped land. Several fundamental concepts lay behind the establishment of what Howard called the Town-Country magnet.

1. The book was originally published in 1898 under the name Tomorrow - A Peaceful Path to Reform. 
These included establishing a finite size to the community, creating a balance between developed and undeveloped land, promotion of a diverse economic base, the use of public and civic spaces to act as focal points in the community, and the establishment of land use zones based on a radial design scheme. It was one of the first approaches that advocated the principles of human scale in its design approach.

The basic form of Howard's garden city was diagrammatic. The approximate size of the garden city was to be about 6000 acres of which only 1000 was to be developed. This early application of an open space requirement left approximately $80 \%$ of the land undeveloped. Howard called this undeveloped area a greenbelt. The remaining 1000 acres was to be developed with the residential, commercial and industrial uses that would be needed to fully sustain the population. The greenbelt would be used for agricultural purposes.

While the basic form of the garden city remained diagrammatic, Howard did outline the lay out of land use within the city. (Figure 2.4) The design was circular with a central park and garden at the center. In the inner rings would be located commercial uses that would service the cities residents. A second ring of residential homes, each with their own gardens, would front along a Grand Avenue. On the outskirts of the circle would lie industrial uses. These would be located along a rail line circling the city. This rail would also be the main link to other garden cities.A 
Figr te 2.4 - Garden City

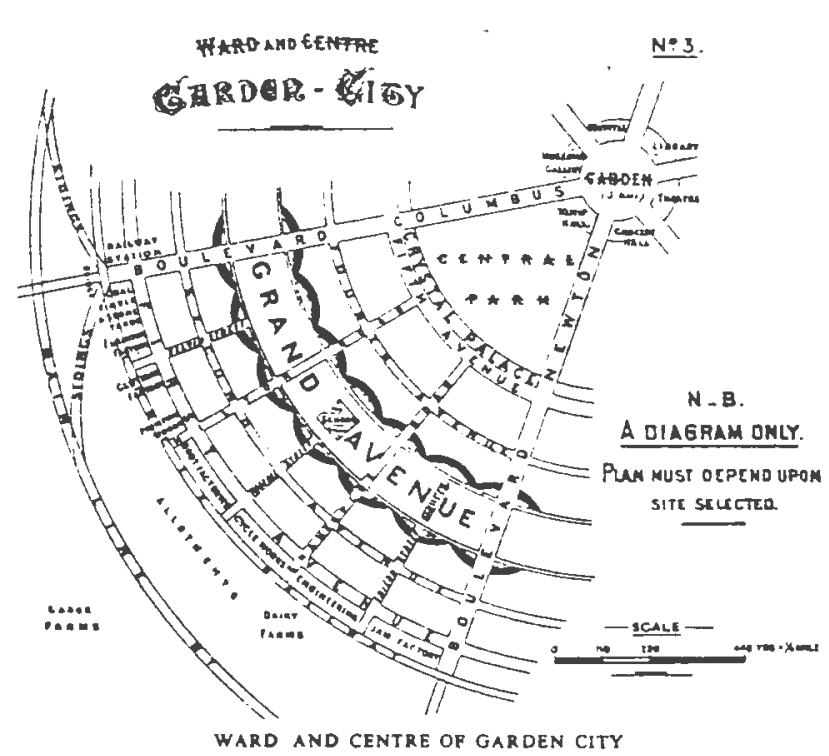

Typical Section of Howard's Garden city showing hierarchy of land use radiating outward from the center. The public spaces are located between the garden and central park. Housing is located on both sides of a grand Avenue. Factories are located along the periphery and are serviced by a railroad. Agricultural uses lie beyond and form the basis for a "greenbelt" between cities.

Source: Garden cities for Tomorrow, 1904.

Figure 2.5 - Regional Plan for Garden Cities

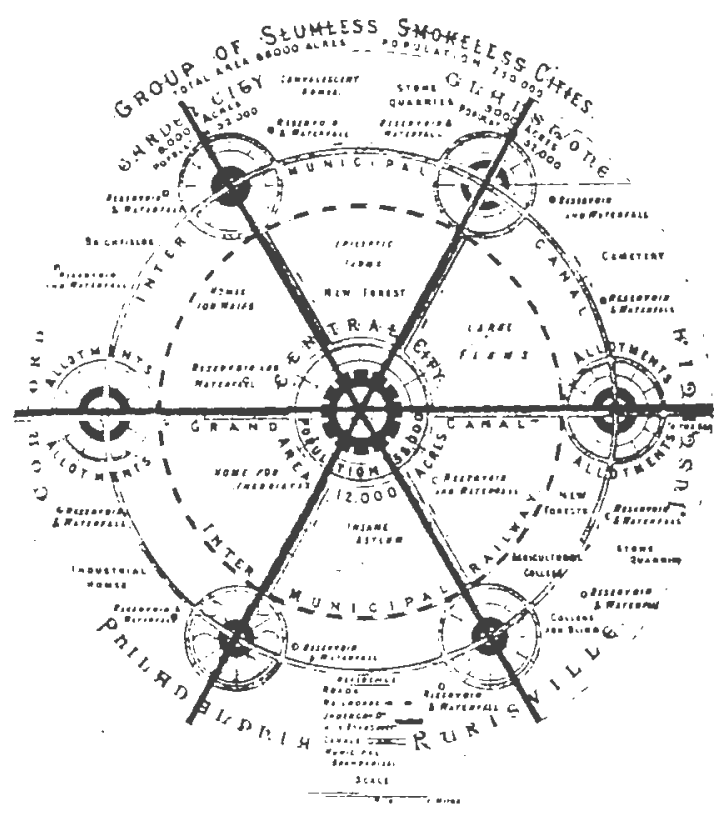

Howard's grand plan called for a collection of garden cities located around a central city. This early example of a Satellite cities concept looked at planning on a regional level. Notice the placement of health and medical facilities outside the cities but used by all. Each of the communities would be self-sufficient providing jobs for its residents within its own town boundaries yet each would be linked to the other by rail.

Source: Garden Cities for Tomorrow, 1904. 
group of garden cities would be arranged in a circular pattern around a central city, undeveloped forest and agricultural land that would serve the agglomeration. (Figure 2.5)

While Howard's grand plan was never achieved several smaller settlements were constructed. The inherent problems involved with private development on such a grand scale plagued both of Howard's early garden cities; Letchworth and Welwyn City. Limited capital prevented the comprehensive development of the entire town. The cost of development resulted in housing costs that were not affordable to all. The limited development of housing delayed the development of commercial and industrial development. Other grand designs such as Toni Garnier's Cite Industrial and Wright's Broadacre city also faced the same problems.

\section{The Neighborhood Unit}

The Garden City Movement was one approach to the rescaling of the urban form. Another route was taken by reformers in urban America. Early reform movements sought to ease the problems faced by innercity neighborhoods by advocating new tenement designs that allowed greater light and ventilation in the center of housing blocks in the city. This did little to relieve the congestion of the urban streetscape.

While the "City Beautiful Movement" carved parks and plazas out of the center of the city, the surrounding neighborhoods were left cramped and congested. By the early 
1900 's some reformers and some city plans called for a more equitable distribution of the "City Beautiful" that included the creation of small parks in urban neighborhoods that would provide a socializing force to its residents.

The idea for a rational approach to neighborhood design in the urban core was created by clarence Perry. This standard "neighborhood unit" was based on two concepts. The first is the notion of a quarter-mile radius as a walkable distance. The second was that the center point of that radius would be the public elementary school. The school was seen as the unifying social force for the neighborhood unit.

The neighborhoods size would be determined by the size of the school and the limits of the quarter-mile radius. Perry proposed a school with an enrollment size of between 1000 and 1200 pupils and calculated a neighborhood population of between 5000 and 6000. This translated into five persons per household which would be considered abnormally high by today's standards. The area of the unit would be approximately 160 acres.

The neighborhood unit would contain all the basic essentials that the community would need. The elementary school would double as the community center providing a place for neighbors to get together. Open space around the school would be supplemented with parks and recreation areas in other areas within the neighborhood. Overall, ten percent of the neighborhood unit would be devoted to open space. Shopping 


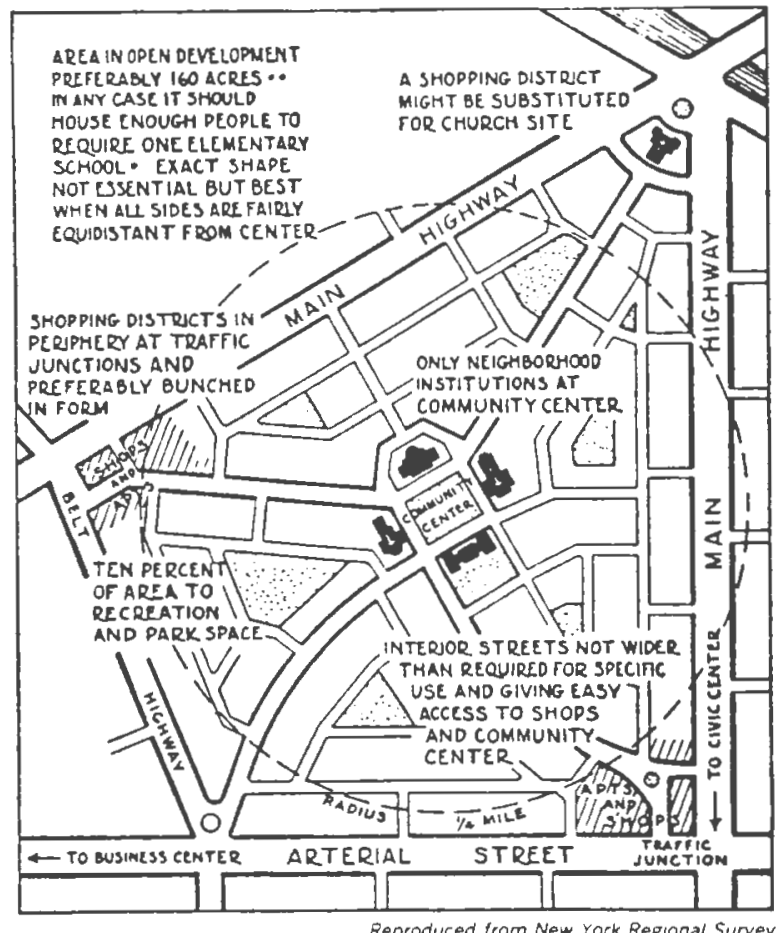

The Neighborhood unit was based on two fundamental princples; the school as the center and the 1/4 mile radius. Arterial streets were diverted around the neighborhood unit while secondary streets inside were designed to avoid through traffic. The commercial nodes were placed on the periphery to take advantage of passing traffic.

Source: The Urban Pattern, 1963.

Figure 2.7 - Neighborhood Unit (c. 1939)

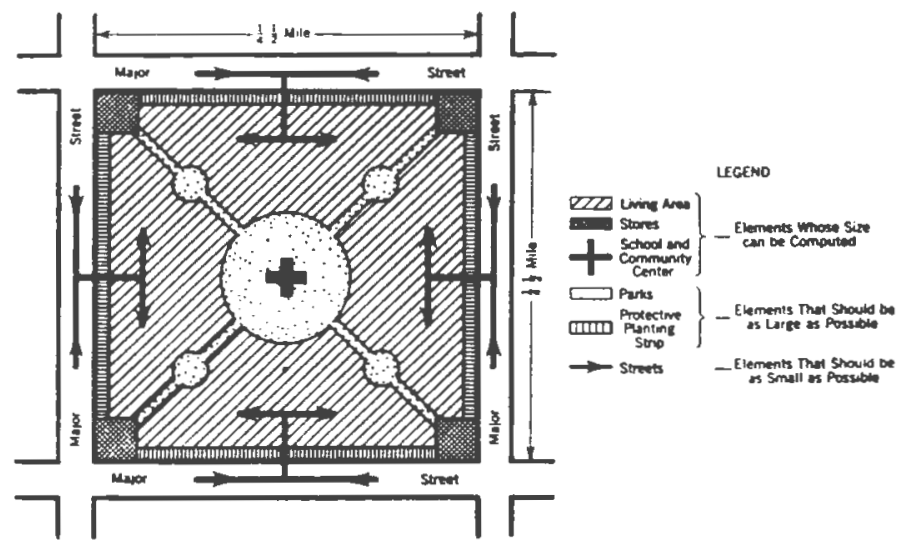

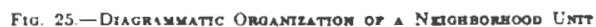

Source: ASCE Manual, 1939.

The neighborhood unit shown above appeared in a handbook on good subdivision design. The neighborhood unit was strongly promoted as one of the better alternatives for subdividing land in the urban core. 
neighborhood unit would be devoted to open space. Shopping areas and some limited manufacturing would be located on the periphery of the neighborhood unit. This would allow the commercial uses to serve residents of the neighborhood unit and those passing by on adjoining streets.

The circulation patterns within the neighborhood units would allow limited automobile traffic but be oriented to the pedestrian. The majority of the urban traffic would be diverted around the unit by the use of arterial and collector streets. The streets within the unit would be limited in width and be designed so as not to encourage through traffic. Perry's early schemes also show main streets in the neighborhood unit terminating on landmarks and buildings.

There are many variations on Perry's idea. (Figure 2.8) Some increased the enrollment of the school. Others increased allowable radius from the center. Changes in either variable would change the total population of the neighborhood. Total populations for neighborhood units have ranged from as low as three thousand people to as high as 12000. Several designers used the neighborhood unit as a module for the design of whole communities. (Gallion and Eisner, 1975, p.283)

\section{Radburn, New Jersey}

The neighborhood unit as a design concept is one of the fundamental principles governing the plan for Radburn, New Jersey. Radburn was also an attempt by its principal designer 
Clarence stein and Henry wright to create a garden city in America. Perry and stein were both involved in the development of American New Towns so it is safe to assume that Perry's neighborhood unit and steins neighborhood unit were being developed from the same ideals.

The basic module of Radburn used single family housing in a half-mile radius around a centrally located elementary school. (Figure 2.8a) A shopping area would be located in the neighborhood to serve local needs. The houses would face an interior park that would provide open space as well as pedestrian access to both the school and the shopping areas. Three of these neighborhoods would form the entire community. (Figure 2.8b) Areas where the neighborhoods overlapped were developed as sites that served the entire community. Large commercial shopping areas, the high school and higher density apartments would be located here. As designed, Radburn would support a population of approximately 25,000 residents.

The unique approach taken at Radburn was the total segregation of Pedestrian and automobile traffic. Housing in the neighborhoods was arranged on cul-de-sacs with the rear of the house facing the street. The street was considered nothing more than a service alley to accommodate the automobile. The front of the house faced a greenway with pedestrian walkways leading to a large open park in the center of the neighborhood. The greenways and parks would allow 


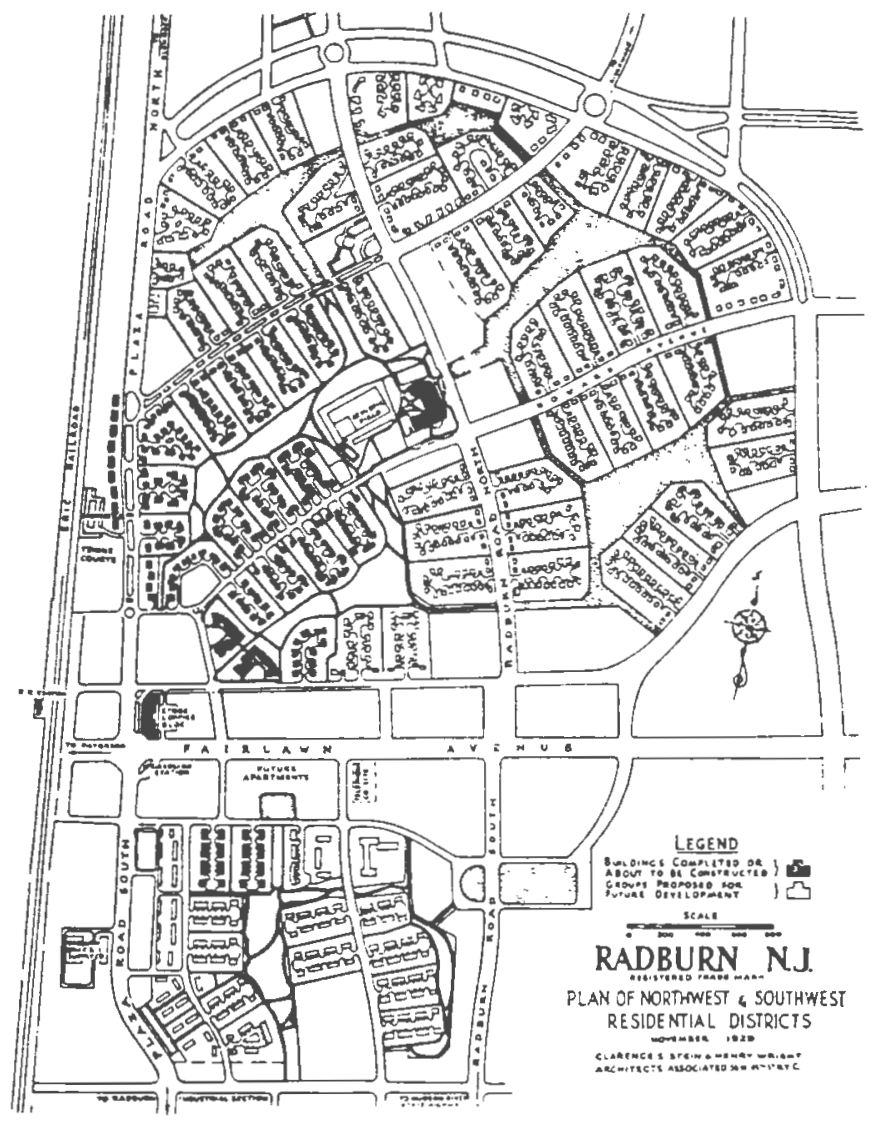

a) Radburn, Neighborhood Unit

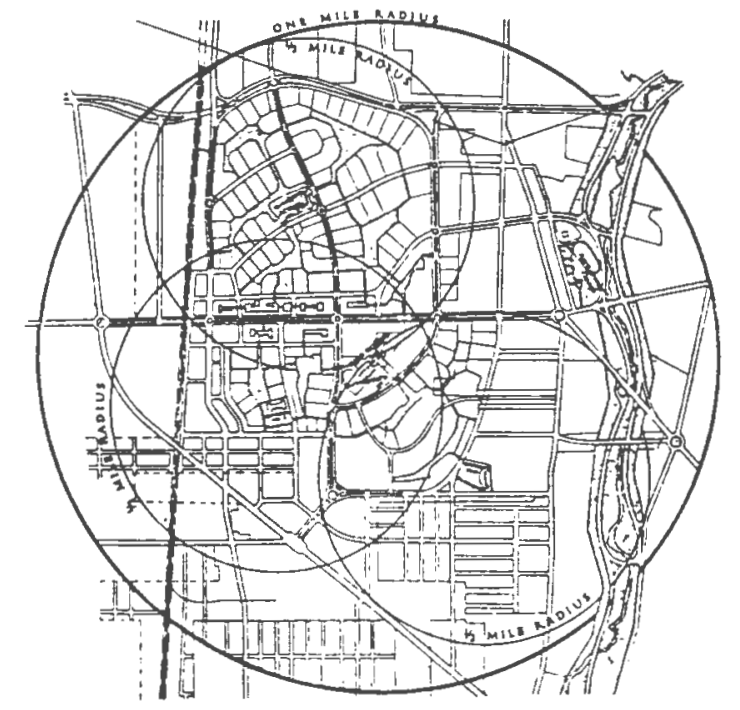

The neighborhood design at Radburn was based on a modification of Clarence Perry's neighborhood unit. As seen in a) the school is at the center of the residential area north of Fairlawn Ave. and is surrounded by open space. Commercial land uses are located along on the south edge of the neighborhood just north of Fairlawn Ave. Radburn made extensive use of cul de sacs as a means to separate pedestrian and auto traffic.

Wright and stein had originally intended Radburn to be the United states first Garden City. However, final plans did not include the greenbelt. Radburn was to be a series of three neighborhood units as shown by the three circles in b). The areas where the circles overlapped would contain regional shopping and office space, multifamily housing and a high school. This would have made Radburn a fairly self-sufficient community.

b) Radburn, Master Plan

Source: Sustainable Communities, 1980. 
residents to move freely within their neighborhoods. The addition of pedestrian tunnels under the main roadways also allowed pedestrians to move between neighborhoods and the main commercial area serving the three neighborhood community without crossing a street.

The plan at Radburn was an attempt by Stein and Wright to develop their own theory of the New Town Ideal. The three neighborhood concept was just one part of an overall scheme that included acjacent industrial use and the addition of a surrounding greenbelt. The remote location of Radburn and the limited capital available made development of the industrial areas and the greenbelt impossible.

\section{CONCLUSION}

The development of the Garden City ideals and the concepts of the neighborhood unit were seen as solutions to the problems of industrialization and urbanization in the late 19th and early 20th centuries. The solutions were based on what the designers felt were the fundamental problems of the urban environment. The unhealthy $\mathrm{mix}$ of uses, the lack of public open spaces and the uncontrollable scale of the city. The solutions all sought in their own way to reproduce a more human scale than had developed naturally.

Howard's concept of limiting size of the garden city and surrounding them with greenbelt was done in the attempt to prevent the spread of the urban environment into the 
countryside. It was a conscious effort to reduce the scale of the built environment to one that could easily be controlled and managed. Its centering focus was the park and adjoining civic and commercial spaces.

The neighborhood unit also established the criteria that there is indeed a limited size to the human environment. It was based on an ideal that the public school is the centering force of the family unit. Where the garden city was meant to be relatively independent, the neighborhood unit was meant to form the basic building block of a larger whole. It was designed to provide scale in the sometimes scaleless urban environment.

The notion of scale disappeared in the development of the suburban environment. The rapid expansion of the suburban environment like the rapid expansion of the urban environment created an urgency for building that transcended the ideal notions of scale and human form. The broad expanses of development characterized by residential subdivisions and the commercial strip compromised the ideals of human scale. While the plans for early subdivisions did include spaces for schools and parks reminiscent of the neighborhood unit, it conveniently neglected the notion of scale that was evident in the reform movements of the early 20th century. Instead it replaced the small town ideal with a pattern of development that was exacerbated by the institution of a zoning ordinance that in essence was scaleless. 


\section{INTRODUCTION}

Most large urban areas usually developed from a series of smaller settlements. Once the dominance of one settlement was established it spread outward from the core to absorb smaller settlements on the fringe. These smaller settlements usually developed into neighborhood centers within the newly incorporated city limits.

Neighborhood settlements located within the limits of the city had many of the ingredients for basic living. First, some form of housing provided a place to live. Second, commercial and some manufacturing areas provided a place to work. Manufacturing employed people to produce the goods. Commercial areas employed people to sell them. While the density and type of settlement changed from neighborhood to neighborhood, the basic ingredients - places to live and places to work - stayed the same.

A similar pattern had developed in the rural areas outside the city. Small settlements dotted the country side providing places to live and work based on the natural resources found in the area. Rivers provided a source for manufacturing. Good soils provided a source for agriculture. While the settlements varied in size and shape based on the resource, the settlement pattern was usually the same; 
residential units provided places to live while manufacturing and commercial structures provided places to work. It is this settlement pattern - a mix of residential, commercial and industrial uses - that has formed the basis for zoning.

How does development happen in communities today and what influences where we place the necessary components that make up today's modern community. The zoning ordinance is the primary form of land use control that almost all communities use to dictate what type of development to allow, where to allow it and at what density. It is based on system of land use hierarchy that at its inception was meant to solve the haphazard development of the urban core yet has resulted in haphazard development outside the urban core.

The reason that zoning has failed in the outlying community is because conventional zoning is scaleless. Without a sense of scale communities have sprawled out across the landscape. This chapter will examine the how conventional zoning has become the primary source of land use control in the United States.

THE EVOLUTION OF SEGREGATED ZONING

Rapid urbanization during the later half of the nineteenth century led to an equally rapid infill of vacant land separating neighborhood settlements in the urban core. This in turn led to an unhealthy mix of density and land uses, that by the turn of the century had become intolerable. out 
of this situation came reform movements that sought to change squalid housing conditions and the city beautiful movement to create parks and open spaces in the urban core.

By 1912, these social reform movements were eclipsed by another theory based on city planning as rational scientific thought. "The city functional"1 centered on the idea of using districts or zones to separate incompatible uses. This idea was based on concepts being practiced in Germany. While there was acknowledgment to the fact that the police powers of the German state were far different than those in the United States, planners and city officials embraced the concept of zoning as an efficient and convenient solution to urban congestion.

New York City is generally regarded as the first major city to prepare a comprehensive zoning ordinance in the United states. It took a simple approach to zoning and divided the city up into three districts; residential; business and unrestricted. One of the major provisions of the districts was the allowance of the lesser economic land use in the zones of higher economic use. Therefore, the business zones could have residential uses and the unrestricted zones (where large manufacturing and industry was to be located) could have both residential and business within it.

1. The city functional is a term used in American City Planning by Mel Scott that describes the growth of the planning movement from approximately 1910-1920. 
It was the zoning ordinance enacted in Berkeley, California (1917) that is considered one of the first zoning ordinances in the country that rigidly sought to regulate land use.(Scott, 1969, p.161) The prevailing train of thought was that if a city keeps industrial uses out of residential districts for reasons of health and safety, then residential uses should be kept out of industrial districts for the same reasons.

This philosophy of segregation based on the Berkeley ordinance - which was necessary in densely populated urban centers - was to become the standard practice of zoning that most communities in the United states have followed for the last 75 years. There was little difference between the method no matter where or what size the community was. The densely populated urban core, the expanding suburban ring and the undeveloped fringe all took the same approach of segregated land use patterns for the establishment of zoning ordinances.

\section{ZONING IN THE URBAN CORE}

The conventional technique of zoning within populated urban areas in the early 20th century was fairly simple; determine the existing use and zone for it. If the use was undesirable, limit the impact by rezoning the area and let the use die out. If it was particularly obnoxious you could declare it a nuisance and get rid of it. This was 
particularly true in the early zoning of cities where urbanization had led to crowded conditions and an unhealthy mix of uses, particularly in areas with heavy industry.

In urban areas, the collection of neighborhoods situated within the urban fabric provided a satisfactory template for zoning. The existing pattern of uses within each neighborhood provided a framework for establishing residential, commercial, and industrial zones. The vacant land areas in between neighborhoods were usually zoned for residential use, with commercial zones placed along major streets. This mimicked the pattern of land use found in many of the existing neighborhoods, wiin one exception. The overlap of uses that tended to occur between commercial and residential zones was discontinued. Some communities actually established standards for designing in the "transitional zones"2 between the segregated commercial and residential zones. New industrial and manufacturing zones were established only around existing areas of intense industrial use. The nature of heavy industry and manufacturing at the time justified this segregation of use.

\section{Subdivision Regulations}

Along with zoning, communities established regulations to control the subdivision and resubdivision of land within its boundaries. The dominance of these subdivision regulations as

2. See Transition Zoning by Arthur Comey published in 1933. 
an integral part of the zoning process is demonstrated by the fact that in almost all communities it is separated from the zoning ordinance and placed under separate cover. Like the zoning ordinance, many of its suggestions for urban improvement have been standardized. In fact, almost all communities in the state of Rhode Island - urban, suburban and rural - use a slightly modified version of the same ordinance based on a 1956 state law.

The basic subdivision ordinance is generally broken down into two parts; 1) the approval process for subdividing land in the community and 2) the design standards that must be followed in order to receive approval for a subdivision.

The approval process for subdivision involves the preparation of preliminary plans that have to be approved by the appropriate authority (usually a planning board or city council). The plans must show all the lots as a result of the subdivision and any roads or rights of way that would be dedicated to the community upon completion. Before the final approval is made a hearing is required before the board or council to give those abutting the property time to voice their opinions on the process.

In order to gain approval all subdivisions must meet certain design criteria established in the subdivision ordinance. Most design standards concentrate on the width, length and construction of road surfaces and the provision of water and sanitary services within the subdivision. Design 
standards regarding lots in a subdivision focus on retaining proper proportions (usually no more than 3:1). All lots created through subdivision must conform to the land use specified by the zoning ordinance.

In 1939, the American Society of Civil Engineers published Land Subdivision, A manual to aid all concerned with the improved standards and practices in the subdivision or resubdivision of land. This manual "prepared primarily for the use of engineers" (ASCE, 1939, p.6) outlined many of the requirements for the subdivision of land in urban areas. In many ways this was more manifesto than manual. It talked of the social benefits of good subdivisions design and promoted neighborhood unit concepts and the use of schools and parks as central features. It also focused on the character of design:

\begin{abstract}
"To be successful the subdivision must compete, not only against other existing subdivisions, but against any subdivision that may be designed in the future. Therefore, the subdivision should have an outstanding character, a distinction of its own, separate and distinct from other areas in the city. It must have definite appeal, an environmental trademark."(ASCE, 1939, p.14)
\end{abstract}

Several changes concerning the layout of subdivisions were occurring at this time. One of the most significant changes was the shift away from the gridiron pattern that had dominated the platting of land. Replacing it was the use of a curvilinear loop pattern of development that was considered "more attractive than the gridiron because it overcomes the monotony and gives each street a special character of its own. 

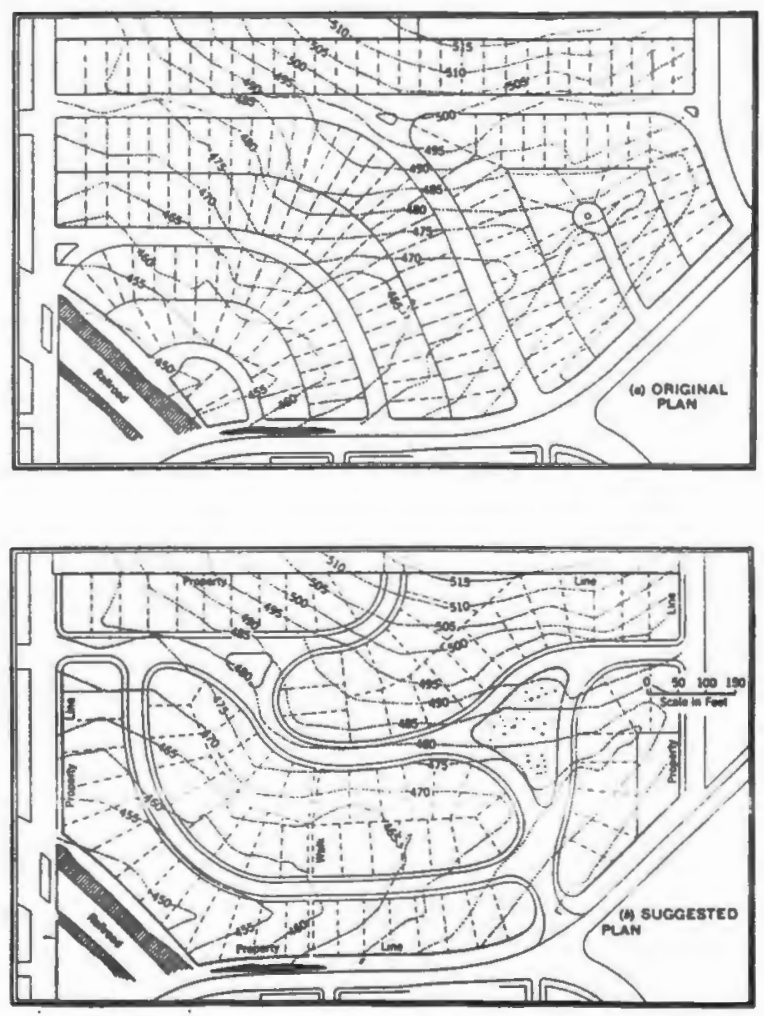

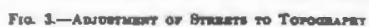

The shift in the design principles involved in subdivision of land had already been established by the time this manual was published in 1939. The suggested plan to the left shows the prevailing attitude toward curvilinear streets that loops. The addition of a road extending to the next parcel was not allowed in many communities.

a.) suggested subdivision road layout
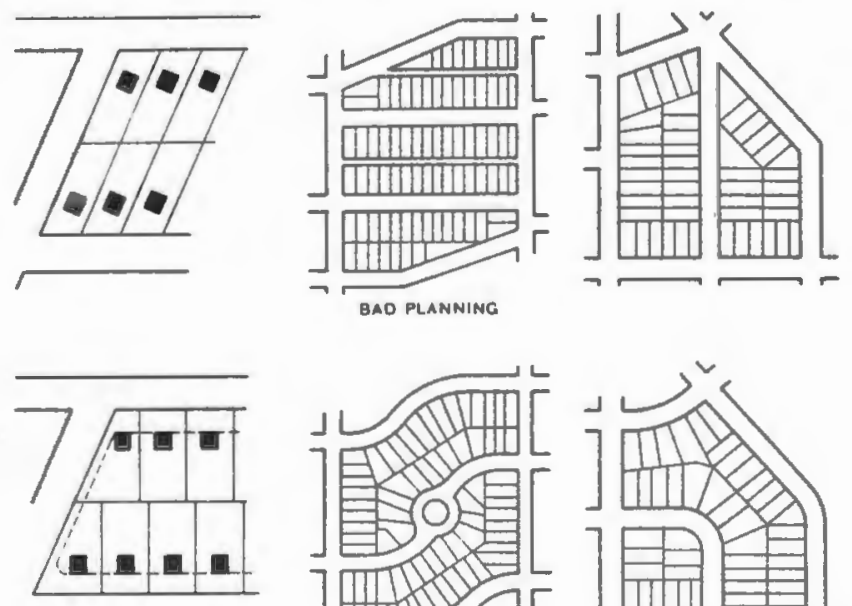

$(4)$

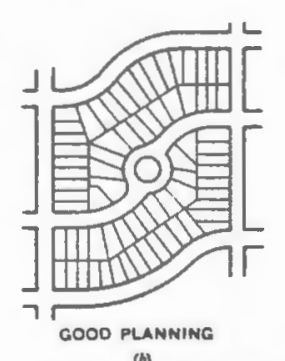

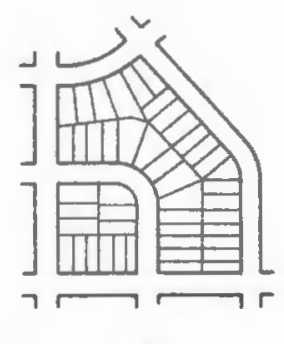

$\Leftrightarrow$

b.) Standards for roads and lots. Source: ASCE Subdivision Manual, 1939. 


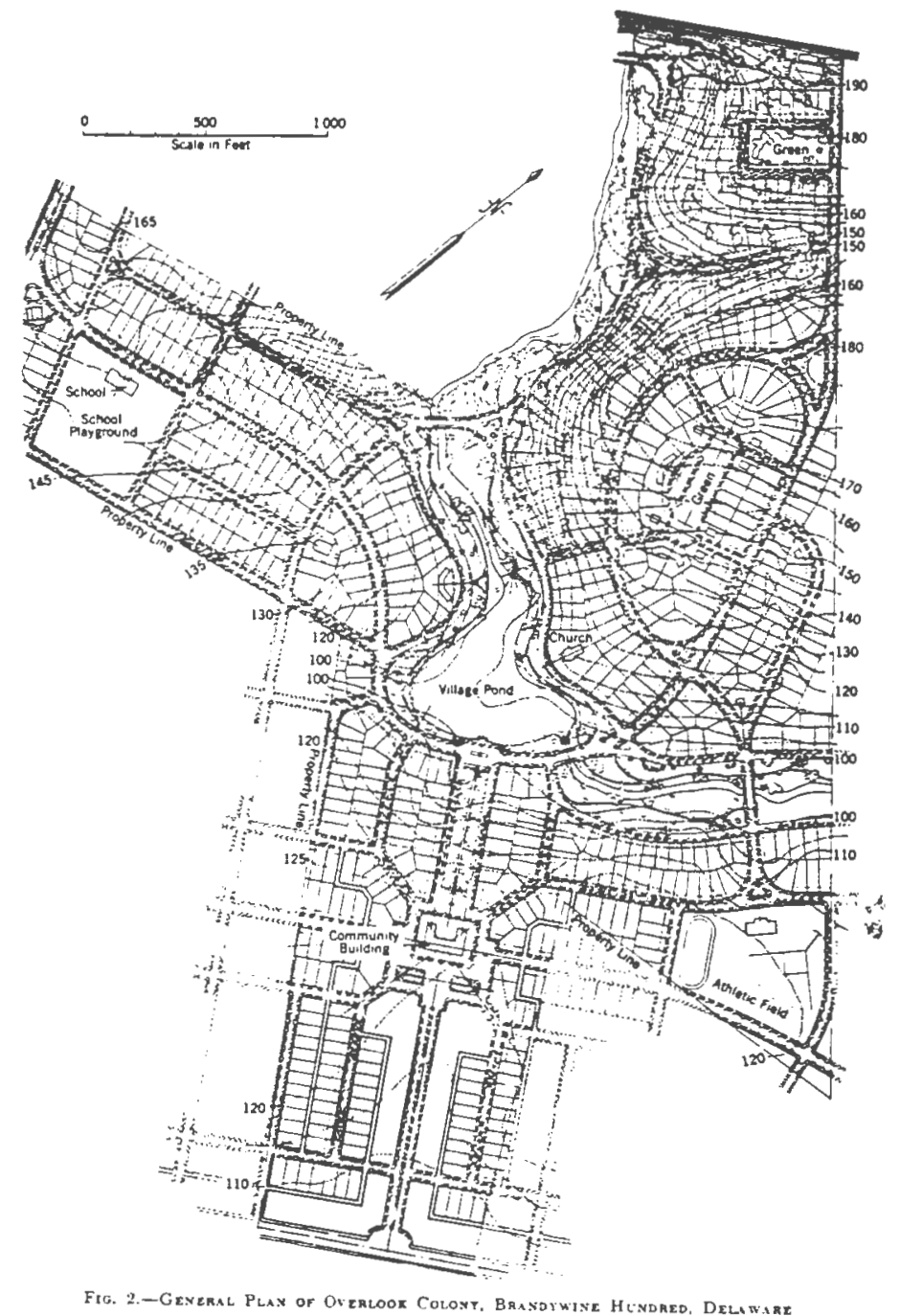

Source: ASCE Subdivision Manual, 1939

This subdivision is used as an example of good subdivision design. There are several key features of this subdivision worth noting. 1.) The project is broken down into neighborhoods each having its own character. 2.) The designers created strong axial elements in the plan even though they use curvilinear streets in the roadway design. 3.) The use of open space within each neighborhood 4.) Vistas are terminated on civic lots or buildings like the community center and schools. 
(ASCE, 1939, p.41) Another important change called for the elimination of the back alley as an unnecessary and uneconomical feature in the automobile age. Instead, planners and engineers promoted the use of cul de sacs. These "dead end" streets eliminated through traffic and allowed residential parking at the front of the house. These two changes in subdivision design would impact development patterns for the next 50 years.

\section{ZONING OUTSIDE THE URBAN CORE}

outside the traditional boundaries of cities and towns laid vast acres of unincorporated land. As the metropolitan regions expanded outward this land was annexed into existing city limits or incorporated to create new municipalities. With the incorporation of land came zoning. The segregated zoning practices established in densely populated urban areas were transferred to these newly incorporated rural lands without the benefits of an existing neighborhood fabric to be used as a template.

settlement patterns did exist in these outlying areas. They generally tended to be made up of smaller and more dispersed communities than those found within the urban core. While these settlements could be zoned based on the existing land use patterns, there were still vast quantities of land between settlements that needed to be zoned. This land was 
usually made up of large parcels that were usually untouched or devoted to agricultural purposes.

In zoning these large parcels, planners inevitably resorted to the standard pattern of zoning established in the cities. Segregate the uses, place commercial development along major roads (or what you think should be major roads) and put industrial uses as far away from everything as possible. In transferring this philosophy to the outlying communities, planners took this basic zoning pattern and stretched it over the landscape. While an urban area could be made up of several different neighborhoods, each one containing several different zones, the entire fringe community was zoned like one of those individual urban neighborhoods. Instead of small clusters of residential, commercial and manufacturing zones scattered over the landscape mimicking traditional settlement patterns, segregated zones were laid over the landscape like blankets covering vast quantities of land in one sweep.

In the fringe community, the multi-family tenement and the row house block has been replaced by the subdivision. The corner store has been replaced by the shopping center with the shopping mall acting as a suburban CBD in a box. The urban workplace has also been duplicated in fringe communities in the form of both the industrial and office park. The invention of the automobile made this transformation possible. The limited radius of pedestrian travel that required a 
variety of land uses within a relatively small area was rendered obsolete by the almost unlimited radius of travel available with the automobile. Yet, the sprawl pattern of development created, in part, by the large size of these segregated districts threatens to overwhelm even the automobile.

Fringe communities zoned large areas of undeveloped land for various residential, commercial and industrial uses. With no existing infrastructure, in place it was left to the developer to build services such as water, waste disposal and roads into the designs. In most cases once the projects were completed this infrastructure was to be turned over to the community. In order to insure that the infrastructure was of quality construction and adequate to the demands of the development, communities instituted regulations regarding the subdivision of large vacant parcels into smaller parcels.

The use of subdivision regulations in the conventionally zoned fringe community has created specific patterns of development depending on the use allowed. Residential zones are dominated by the single family house subdivision. The use of the automobile allowed immense tracts of land to be laid out with curvilinear roads looping around the landscape sprouting cul de sacs like buds on a tree limb. This pattern of development generally tended to ignore (or in many cases was not allowed) connections with adjoining subdivisions. Instead traffic was funneled from the cul de sacs onto streets 
in the subdivision acting as collectors to deposit vehicular traffic onto main roads (arterial) that serviced the community.

The early subdivisions (like Levittown) that contained thousands of houses tended to follow the early guidelines for subdivisions and contained parks, schools and community centers. As growth continued, the parcels being subdivided became smaller and the justification for providing amenities became harder. Why provide amenities when a park or community center was just a ten minute drive away? As a result, the spaces that would give subdivisions their character were no longer included.

The scale of development patterns created by zoning and subdivision patterns outside the core resulted in another problem. Very few residents were within walking distance of shopping areas. To get to a store you had to drive. Since arterial streets were being designed to carry the bulk of a community's traffic it only made sense to locate commercial uses along them in long strips. Urban areas had commercial buildings laid out along their main streets and the neighborhood unit laid out commercial properties on the arterials diverting traffic around the neighborhood unit.

The reliance on the automobile for shopping created the need for large amounts of parking. This parking was usually placed in front of the store. Frontage parking pushed the commercial buildings to the back of the site. Because the 
buildings were now set far back from the road, large signs had to be erected to catch the attention of motorists. As traffic on roads increased the commercial strip stretched on down the road to accommodate it. The collection of subdivisions began to sprawl outward toward the fringe.

\section{Planned Unit Development}

One of the results of sprawl pattern development was a loss of community identity. One subdivision looked like any other. Commercial strips stretched like a ribbon down the sides of highways. The sprawl of development created a sprawl of services. Town halls, schools and libraries were scattered across the community. No one area of a community could be perceived of as its center. In response to this many communities amended the zoning ordinance to include provisions for creating developments with a mix of uses on one parcel of land to create both community character and sense of place. Planned Unit Development (PUD) was seen as the answer to the problems of conventional zoning. PUD is not zoning; its anti-zoning. Its a hole created in the conventional zoning fabric that allows a developer to build whatever a community (or more often community leaders) feels is necessary. PUD is the a legal exception to the rules of the zoning game.

The definition of a PUD is hard to describe since it can vary greatly from one community to the next. PUD has generally come to mean an allowance of a mix used concept that 
is not allowed in conventional zoning. But this is not always the case. Some PUD's are limited to residential use (sometimes called Planned Unit Residential or PUR) while others prohibit residential use (in the case of an industrial PUD). Some communities limit the placement of PUD's to certain districts. Others limit the type of use allowed in a PUD based on where it is placed. For example, if a PUD is placed in a residential zone the PUD, the dominant use within the PUD must be residential even though a mix of uses is allowed. The community establishes the parameters of the PUD based on its goals and objectives through a comprehensive planning process.

Initially, the PUD is not tied to the land. It is a floating zone that is left up to the discretion of a developer to request. The process for establishing a PUD is similar to that of a subdivision. Preliminary plans are submitted to the proper authorities (usually the local planning department) that show proposed land use and design. A series of hearings take place that weigh the merits of the proposal against community goals and allow abutters and concerned citizens to voice their opinion. If the project is approved and built the community's zoning map is amended to show the presence of the PUD zone.

The reasons for a community choosing to adopt a PUD ordinance are almost as varied as the different PUD ordinances in use. The most common reasons are to promote flexibility of 
land use within the community, promote a more diverse housing stock, protect and preserve open space, allow amenities for large projects that would cost too much for a community to provide, and streamline the zoning process on large projects. The city of East Providence, Rhode Island lists nine objectives for PUD:

1.) To promote more economical and efficient use of the land while providing harmonious housing choices and opportunities:

2.) To promote flexibility in design and diversification in the location of structures;

3.) To promote beyond that required by any other law, ordinance rule or regulation which may be applicable, the preservation of natural scenic qualities of open space of existing landscape features, of site amenities, of recreational opportunities and of historic features;

4.) To promote greater flexibility and consequently more creative and imaginative design for the development of residential areas than is generally possible under conventional zoning regulation;

5.) To ensure a harmonious, safe and beneficial relationship between the planned unit development and adjacent and nearby areas;

6.) To give developers reasonable assurance of ultimate approval before incurring the cost of final design and engineering while providing assurances to the city and the general public that the approved project will meet with approved objectives;

7.) To coordinate the site plan review process by integrating both subdivision and zoning controls into one public review mechanism and, thereby, save time, effort, and expense for both the city and the developer;

8.) To further the goals and objectives of the East Providence master plan, to promote the public health, safety, morals and general welfare, and to further the objectives of Rhode Island General Laws 45-24-3; and,

9.) To encourage the conservation of energy resources. 
In essence PUD is supposed to do everything that conventional zoning does not. If the East Providence PUD ordinance is typical, then conventional zoning does not promote economical and efficient use of the land, does not promote imaginative design, does not promote the preservation of natural scenic qualities and open space, and does not encourage the conservation of energy resources.

\section{CONCLUSIONS}

The conventional pattern of zoning is fundamentally different from the way mankind has traditionally settled. The problems stem more from the lack of scale than from the segregated patterns of use chosen. The shift from small settlements with an overlap of land uses easily reached on foot has been replaced with one that dictates use of the automobile. Where several small settlements within an urban area could be serviced by public transportation, scaleless settlements on the fringe are so spread out that public transportation is not a viable option. Where the variety of settlements in the urban area offered a range of alternative and affordable housing, the fringe with its limited residential uses offers limited alternatives.

Conventional zoning arose out of a time of crisis. The congestion and unhealthy atmosphere of the late 19th century dictated change. The congestion of the "suburban city" and the unhealthy atmosphere it has created has created another 
crisis that is dictating another change in the fundamental concept of land use and development. 
New Design Trends in Suburban Planning and Design

\section{INTRODUCTION}

The solutions to sprawil patterns caused by conventional zoning techniques presented in this chapter are not really new. The theoretical basis for Performance Zoning took shape well over 15 years ago in Bucks County, Pennsylvania. It is seen as a replacement to conventional zoning. The concepts of Neotraditional and Pedestrian Pockets have been around for about a decade. They are alternatives to the traditional subdivision and PUD that dominate the conventionally zoned community. The purpose of this chapter is to expose the reader to these alternatives and suggest that there are more choices that a planner can make when addressing the problems facing the fringe community; how can we develop a future without destroying the past.

\section{PERFORMANCE ZONING}

This alternative approach to conventional zoning is attributed to Lane Kendig, who literally "wrote the book" on it. Zoning was originally established to protect the health safety and welfare of a community but according to Kendig,

"... its promise as an effective land use measure for the implementation of plans has not been fulfilled. Zoning has failed to protect the environment: forests have been felled, floodplains and marshes have been filled..., and agricultural land has been destroyed." (Kendig, 1980, p.3) 
In 1974 Kendig, then Director of Community Planning for Bucks County, Pennsylvania, grappled with the inflexibility of local zoning ordinances and the mediocrity that it inevitably produced. Attempts to modify the conventional ordinance did not prove promising. "A more radical approach was necessary." (Kendig, 1980, p.3) That new approach has come to be known as Performance Zoning.

Performance Zoning is based on the premise that all land is unique. The size, shape and natural resource features found on one piece of property can be radically different from the next. Any or all of the following combinations; differing soils types, the presence of ponds, streams and wetlands, steep slopes or unique landscape features, can complicate the development of any site. Yet, conventional zoning imposes on this landscape a rigid set of rules using minimum lot sizes, and standardized road design with limited flexibility regardless of the unique features the land may contain. This ultimately results in the inefficient use of the land, the eradication of important natural features and the creation of bland lackluster designs.

\section{Design Variables}

Performance zoning looks at the landscape differently. It is predicated on the fact that development should accommodate the natural landscape, not the other way around. It regulates development on the basis that the important thing 
is to protect the land, yet permit developers the flexibility to maximize the use of this land. Four variables are used in performance zoning to determine land development; an open space ratio, an impervious surface ratio, a density factor, and floor area ratio.

Open Space Ratio measures the amount of public open space left on a site after development. The protection of large parcels of open space serve a valuable recreation and conservation function and can help preserve the character of a rural or agricultural area. The ratio is determined by dividing the acres of open space left after the subdivision of private property by the gross site area. For example, a conventional subdivision that divides the entire parcel into privately owned lots would have an open space ratio of 0.00 .

Impervious Surface Ratio measures the amount of surfaces on a site that do not absorb rain. This can include buildings and any area paved with concrete or asphalt like driveways or sidewalks. Stormwater runoff and groundwater recharge can be severely impacted by the presence of impervious surfaces. It can lead to soil erosion and flooding. The ratio is determined by dividing the total acres of impervious surfaces designed for a site by the gross site area.

Density is limited to the development of residential land expressed as number of dwelling units per acre. In performance zoning a density factor is based not on the gross 
density of an entire site, but on the number of dwelling units per net buildable land (net density).

Floor Area Ratio is used in nonresidential calculations and is a familiar to most planners and architects. It is simply the sum of the total area of all floors in a building divided by the gross area of the site. This calculation is helpful in determining the impacts of nonresidential buildings which may contain a wide variety of uses.

These variables are used as the basis for zoning Standards for each variable are set that will adequately protect the environmental quality or the character of an area. An area with poor soils might require developers to adhere to a lower ratio of impervious surfaces. Another area with outstanding environmental character might require a higher ratio of open space on a site. These areas can be designated as districts with the variables adjusted to achieve the desired result

\section{Performance Zoning Districts}

Dividing a community up into districts is still required with Performance zoning. There are even restrictions on land use in certain districts. Heavy industry is still heavily segregated with performance zoning. The main difference between conventional zoning districts and performance zoning districts is how the protection of land and the control of growth is achieved. 


\begin{tabular}{||l|l|l|l|l||}
\hline \multicolumn{5}{|c|}{ TABLE 4.1 } \\
\multicolumn{5}{||c|}{ Example of Performance Zoning Districts and Variables } \\
\hline District & Open & Imperv. & Max. & Net \\
& Space & Surface & Gross & Density \\
& Ratio & Ratio & Density & \\
\hline Wilderness & .98 & .01 & .07 & 3.5 \\
Agricultural & .90 & .05 & .22 & 2.2 \\
Conservation & .85 & .06 & 1.00 & 6.6 \\
Rural & .80 & .08 & .70 & 3.5 \\
Estate & .50 & .08 & .48 & 0.96 \\
Development & .56 & .56 & .75 & 1.7 \\
Urban Core & .25 & & 10.5 & 14.0 \\
\hline
\end{tabular}

In conventional zoning land that is determined to be environmentally sensitive is "down zoned". That is, the zone is usually limited to residential development on large lots (usually from two to five acres). While this may insure that the land stays largely undeveloped, it does not prevent sprawl. It simply spreads it out. Performance zoning uses the established variables and the natural features of the land to control how the land is developed. As part of a coherent and intelligent planning policy, environmental and geographic considerations of the landscape are used to set the variables for each district. It is the carrying capacity of the site that determines development.

\section{Carrying Capacity}

For a developer to determine how land can be developed the carrying capacity of the site must be determined. First, all resource restrictions on the property must be deducted 
from the gross acreage. Resource restrictions are listed in the zoning ordinance and may include flood plains, wetlands, shorelines, and steep slopes. second, a requirement for recreation must also be satisfied. This is usually a small percentage $(.10)$ of the remaining land that must be set aside for active recreational use. Third, the total acreage of resource and recreation restricted land must be checked against the open space ratio for the district. If the total acreage for the restricted land does not equal the land required as a result of calculating the open space ratio then more land must be set aside. What is left after all these calculations is a net buildable area on a piece of property. The developer uses the net buildable area to determine the number of dwelling units allowed by multiplying this against a density factor allowed for the district. Using a 100 acre parcel with an open space ratio of .80 and a density factor of 3.5, a developer could locate 70 units of housing on 20 acres of the land. If resource restrictions only allowed 15 acres of land to be counted as net buildable land then the developer would be limited to only 52 units on the site. Limiting development to the carrying capacity of the site makes developers look at potential sites much more carefully before purchase. What makes performance zoning attractive to the developer is the flexibility of building type built into the ordinance. 


\section{Site Development}

Performance Zoning provides flexibility with respect to site design. The developer is free to use the standard subdivision design and "max out" the net buildable area with single family house lots or the site can be designed using a performance subdivision design available in the code. Several varieties of housing types - both single and multifamily with different lot sizes and setback requirements can be built on the site. (Figure 4.1) It is possible to mix a variety of housing types and, in those districts that allow it, mix uses on a site. The variables established for each district control the size of the project.

Regulations appearing in conventional zoning ordinances that address parking, lighting, landscaping, and roadway design also appear in performance zoning standards. There are also provisions for historic districts and design guidelines if a community desires. Performance zoning offers fringe communities a flexible alternative to conventional zoning that, if tied in with comprehensive planning, can help to eliminate sprawl pattern development in the future. 
Figure 4.1 - Performance Zoning Housing Types
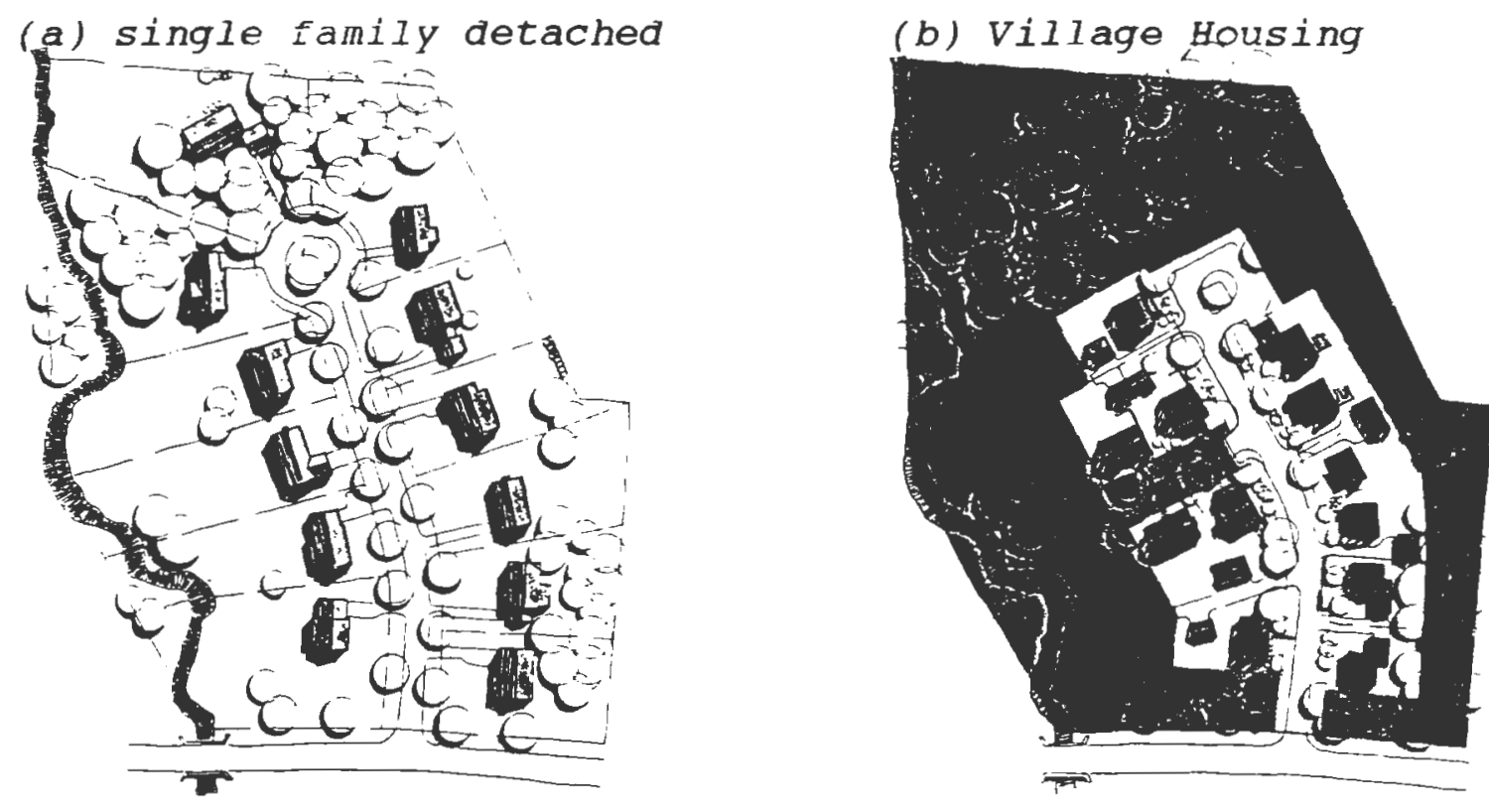

Open Space Ratio - .00

Open Space Ratio - .65

\section{(c) Weak-Link Town House}

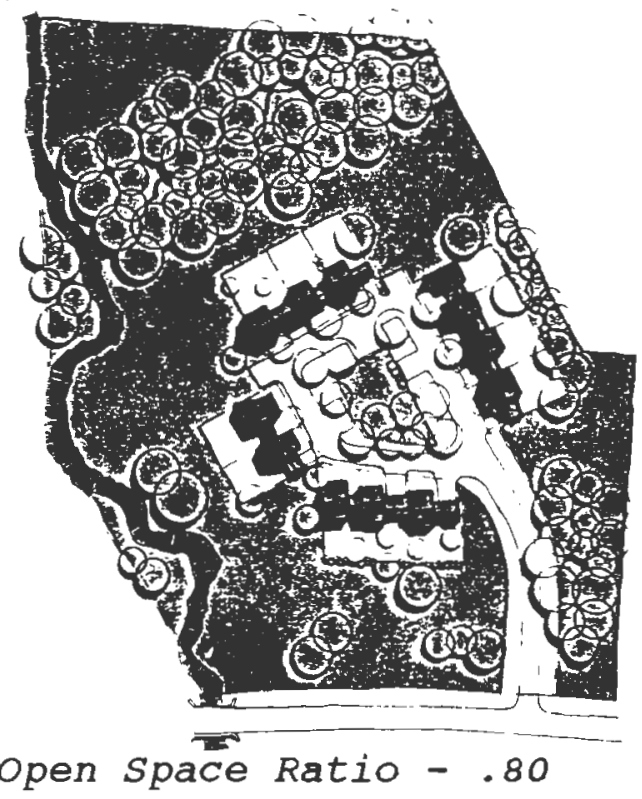

(d) Apartments

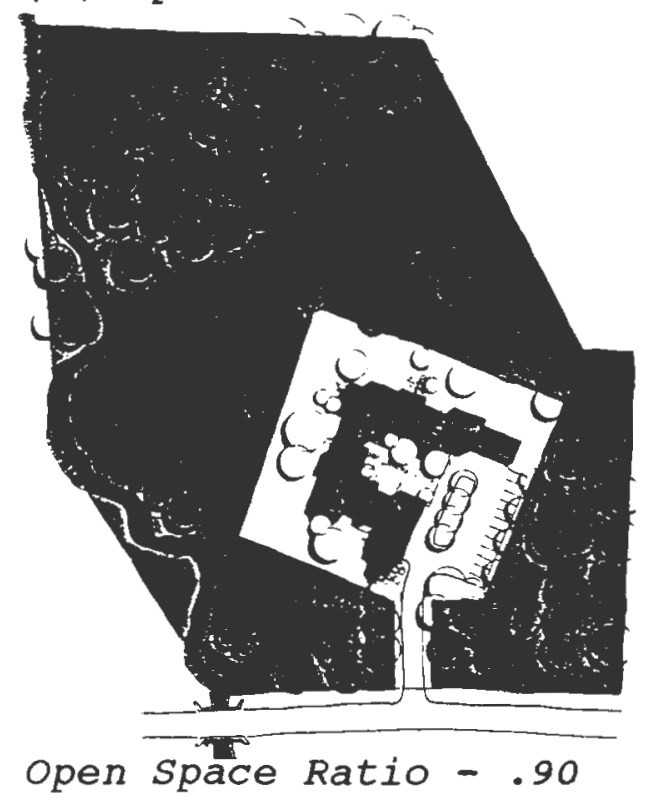

The plans shown on this page are just four of the eight housing types allowed under Performance Zoning. The density on the site is 1.55 for all the plans yet the amount of open space steadily increases as the housing types change from the conventional subdivision (a) to multifamily housing (d). Source: Performance Zoning, 1980. 


\title{
NEOTRADITIONAL TOWN PLANNING
}

The movement for neotraditional town planning is based on a return to classicism that has been hotly debated in the architectural and planning professions over the last decade. The return to a more classical form was a backlash to the modernist design concepts that were widely accepted following the second World War. The stark simplicity of the modern ideal was summed up by Robert Venturi in his book Complexity and Contradiction in Architecture. In describing the segregation of use in Philip Johnson's Wiley House Venturi said ;

\begin{abstract}
"the building becomes an oversimplified program for living - an abstract theory of either-or. Where simplicity cannot work, simpleness results. Blatant simplification means bland architecture. Less is a bore." (Venturi, 1977, p.17)
\end{abstract}

Neotraditional planning is a return to more classical forms represented by small town ideals; walkable mixed use neighborhoods with conveniently located civic spaces where people can come together. It is in someway more philosophical than physical, promoting neighborhoods where residents can journey down to the town center for a cup of coffee and the paper and relax with both on the town square. There are several variations on the neotraditional concept but all of them work with several basic tenets; a finite and limited size to development, the concept of mixed uses, the concept of usable open space in the form of a greenbelt along the edge and commons or parks in the middle, the concept of civic 
spaces, and a design principle that uses vistas terminated on focal points.

\section{Traditional Neighborhood Development}

The Traditional Neighborhood Development ordinance (TND) for short was developed by the firm of Duany Palter-zyberk of Miami, Florida. As can be seen by the model on page 52 it is a simple ordinance covering only two pages. It is meant as an overlay district and is an alternative to the conventional mixed use PUD ordinance adopted by many communities. The TND embodies the planning principles of its authors; that planning is more than physical, it is social, and even spiritual. According to Andres Duany the TND goes beyond the limits of conventional zoning's "horizontal infrastructure" of traffic flows, parking availability, and land use density. It creates a "vertical infrastructure" of human social interaction of daycare and community centers, through the use of space, not land.

\section{Design Criteria}

The main feature of the TND is its finite size; no less than 40 acres, no more than 200 acres. On extremely large parcels of land the several TND's would be designed for the site. Each TND would have the resources to stand on their own with the provision for regionalization of some services that a single TND might not accommodate. 
Figure 4.I

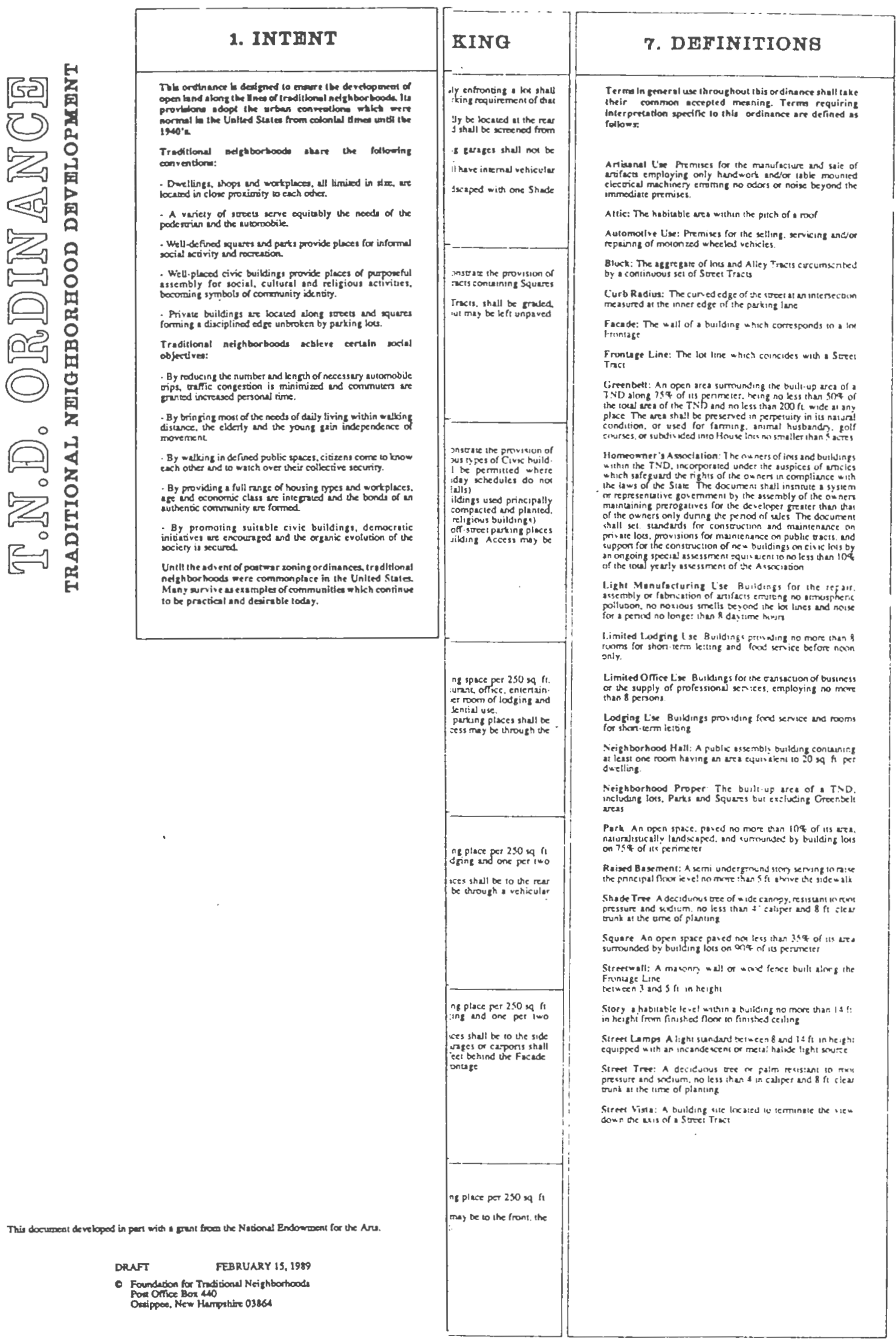




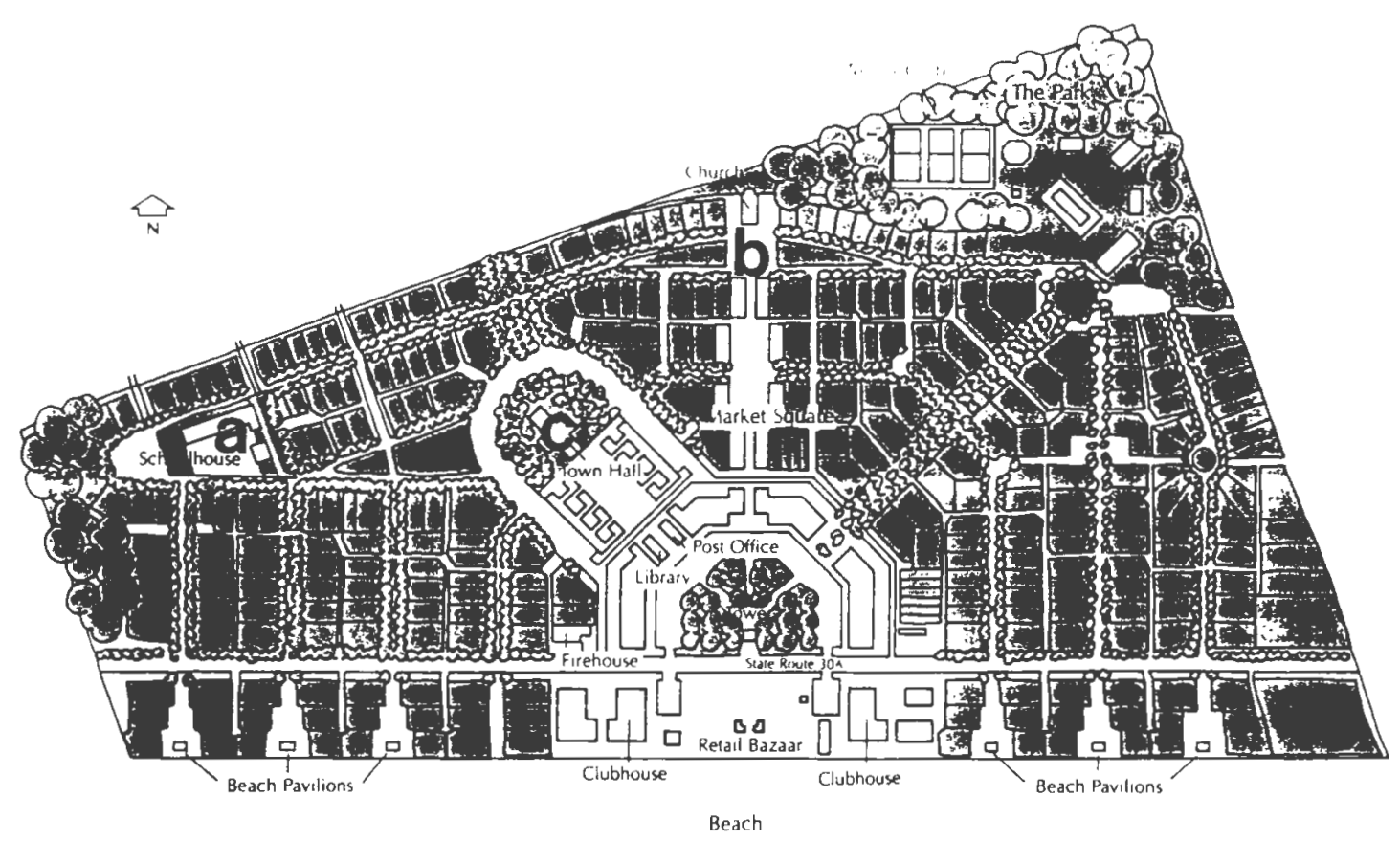

Source: ULI PRF, VOI. 16, NO. 16, 1986

The development at Seaside, Florida was one of the first neotraditional town plans and is also the most widely known. The strong emphasis on design and scale that characterizes neotraditional town planning is evident at seaside. The entire site is only 80 acres yet it contains 550 residential dwelling units on only $30 \%$ of the site while leaving almost 408 of the site used for public open space. (ULI PRF, Vol 16) Neotraditional design elements include the use of a grid iron street lay out with alleys along rear lot lines between streets and the use of civic lots and buildings, like the school house (a), church (b) and Town Hall (c) to terminate vistas on major axes. It is interesting to note that many of these same features appear in the example of good subdivision design in Figure 3.2 
- Figure 4.3 - Deerfield TND in Merriville, Indiana

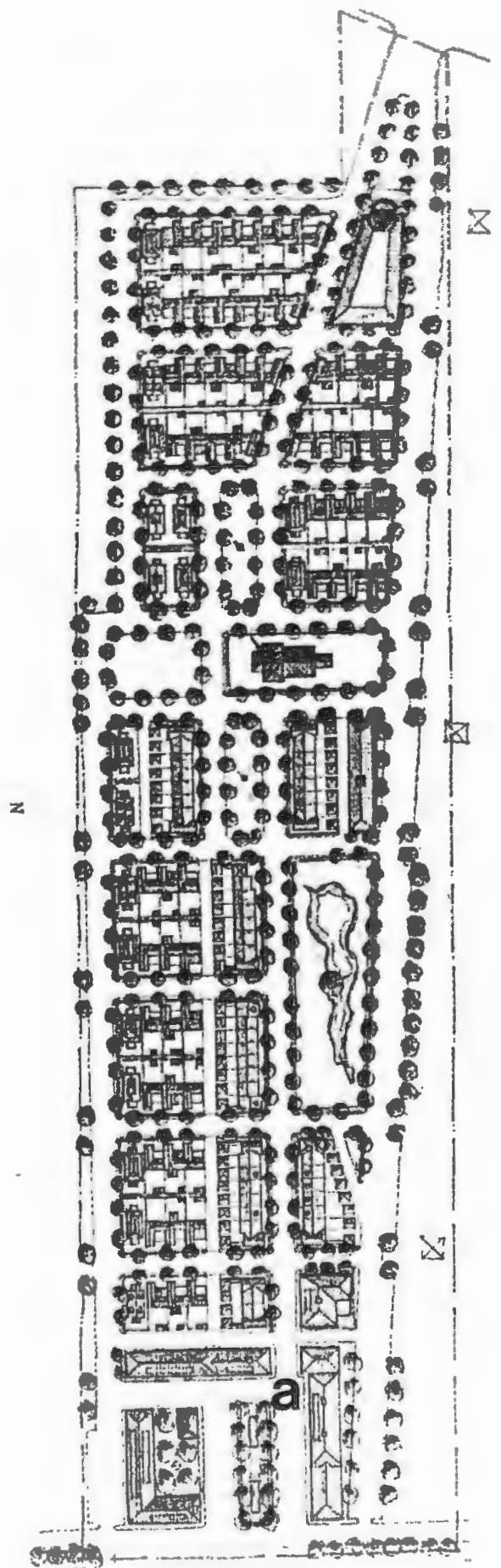

The TND of Deerfield is located in Merriville, Indiana and demonstrates the variation of design that can be achieved in neotraditional planning. The lay out of the 40 acre site has been modified to place the commercial center (a) on the TND's eastern edge to front an existing highway. other than that the TND design principles are still intact.

The design team at Deerfield also included a "built out" master plan (below) for the area showing how TND standards could be used to weave adjacent sites into an overall town fabric. The sites could be developed individually with site plan and design guideline review to insure that the integrity of the grid is maintained. Notice that the street layout in Deerfield locates access roads on the property lines to ease the transition between adjacent properties.

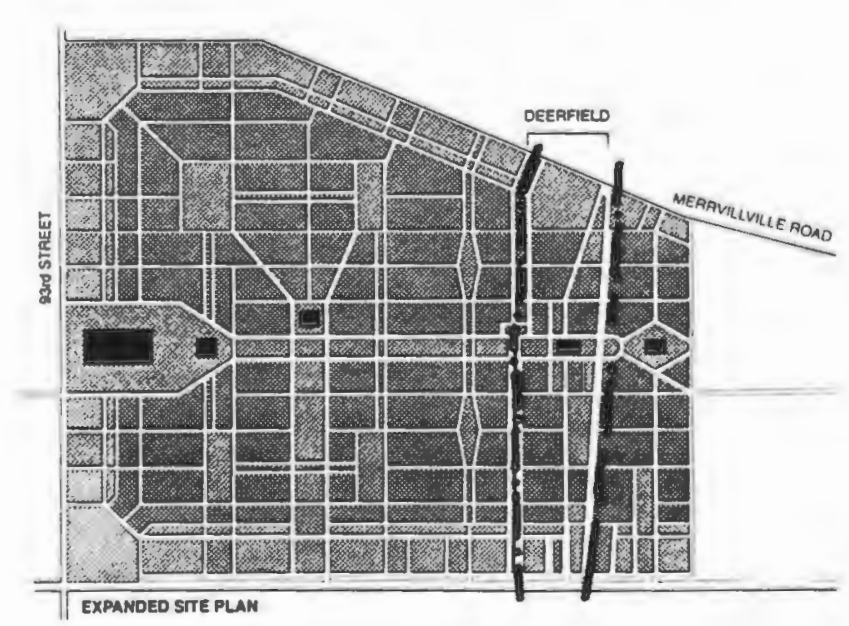

(b) Master Plan (a) Deerfield site Plan Source: PA Magazine, May,
1989. 
A local transportation loop could be utilized to move people between different neighborhoods. This is made possible by the fact that the TND is not made up of a series of cul de sacs and collectors. Road design in the TND is envisioned as a network of streets and alleys that allow alternatives in travelling from point $A$ to Point $B$.

The second feature of a TND is the reuse of an old concept; the greenbelt. As seen in section 7 of the model ordinance, the greenbelt must surround $75 \%$ of the site's perimeter and not be less than $50 \%$ of the TND site. This ensures that in a maximum TND of 200 acres, a 100 acre edge will be kept preserved in perpetuity. The greenbelt concept fights the typical sprawl pattern of development by keeping adjoining developments from encroaching on each other while still allowing the land in between to be used.

A third feature of the TND addresses Duany's concept of vertical infrastructure. Provisions for civic lots to be used for community centers, daycare facilities, and even churches are required within each TND. While the lots are set aside during the design phase, the buildings themselves do not have to be constructed until the TND is partially occupied. This reduces upfront costs to the developer and makes the provision more acceptable. ${ }^{1}$

1. While a civic lot for daycare is required, the developer is not required to build a daycare center. Even Duany admits that the legal and insurance problems facing the daycare industry fall beyond the scope of TND's. 
The fourth feature of the TND has to do with the classification and $\mathrm{mix}$ of land use. As can be seen from the model ordinance, land use is not tied directly to the land. This is, of course, helped by the fact that the entire site is being developed at one time. What is interesting is the mix of what are traditionally segregated uses based not on use but on building type. There are no commercial and residential zones in a TND. There are shopfronts, workshops and houses, that are differentiated by how they are built, not where they are built.

The use of the TND ordinance actually gives communities more control by giving up control. Developers are given a specific set of guidelines that are fairly simple. Unlike impact fees and development exactions, that allow a community to provide off site amenities for development, provisions for open space and community services are built in to every TND. While every public service cannot be provided for in a TND, (libraries, schools, and rescue services for example), small neighborhood amenities (parks, meeting halls, and post offices) are provided. The TND ordinance represents a viable alternative to the conventional pattern of subdivision and strip commercial that dominates the fringe community.

\section{New Hamlets and Villages}

This concept is very similar to the TND approach. It has at its core the same fundamental values; preservation of open 
space through the use of buffer zones and commons, a mix of uses on the site, the termination of vistas on focal points and design principles that encourage pedestrian activity. If the TND is meant to evoke an image of an active and bustling little town center, then the hamlet and village design evokes the image of a small rural village you might encounter along a country road.

Anton Nelessen and Associates of Princeton, New Jersey has defined the Hamlet and Village concept and offers it as an alternative to conventional subdivision design in fringe communities. The basic unit of design is the Hamlet. Several Hamlets designed on a large site create a village. Hamlets designed separately on adjoining sites can also be linked to form a village. This allows smaller separately owned pieces of property to be developed.

\section{Design Criteria}

The design criteria for a Hamlet is not based on an ordinance like the TND, but on guidelines that Nelessen and Associates have developed over time. However, it is possible to craft the Hamlet characteristics into an ordinance similar to the TND. This is more cluster design than PUD.

The question of size is not based on acreage minimums and maximums like the TND. Instead, it looks very similar to performance zoning standards. A site density of two units per gross acre is the maximum allowed and $50 \%$ of the site must be 
preserved as open space. Part of the required open space is to be a "town common" located on the site. It is around the town common that mixed use development (commercial and residential) will be located. The rest of the development is limited to single family and duplex housing.

The presence of mixed use within the Hamlet design is meant to accomplish several things. First, the clustering of commercial uses within the Hamlet decreases the need for commercial strips within the community. Second, the residential units above the commercial property help commercial property owners offset the cost of development and create affordable residential units. Third, the cluster of commercial units within easy walking distance from a compact residential neighborhood creates population nodes that can act as service points for public services and public transportation.

Within the residential section of the Hamlet, design standards are used to create an environment that is not only appealing but economical. Smaller residential lots make units more affordable. Shallower set backs (10 to 15 feet) than those found in conventional subdivisions (30-35 feet) create more space in the back yard even though the lots are smaller. Garages that are typically placed along the front setback in a conventional subdivision are placed to the back of the site in a Hamlet. On larger lots in a Hamlet these garages can be designed with accessory apartments, allowing the homeowner an 
additional income source or accommodate an extended family arrangement (parents or older children).

Other design criteria include limiting the width of road right of ways to 34 feet. This is enough to provide two twelve foot travel lanes, with a four foot sidewalk and three foot planting edge on either side of the street. Along the common an eight foot parking lane would be added to allow on street parking. The layout of the road system should take advantage of vistas that terminate on focal points. Landmarks such as flag poles, clock towers and the common should be used as focal points.

The Nelessen promoted Hamlet and Village Concept has become an integral part of the state of New Jersey's comprehensive development and Redevelopment plan entitled Communities of Place. The guide sees the use of Hamlets and Villages as way to prevent sprawl patterns of development from continuing to spread into rural and undeveloped sections of the state.

The guide plan outlines the following characteristics for the establishment of hamlets:

1.) The new hamlet is a residential settlement located at, or set off from, a rural crossroads...;

2.) The hamlet area may support a resident population corresponding to an average population density of 1000 or more persons per square mile and contain a resident population of less than 250 persons;

3.) The new hamlet area would contain primarily contain residences;

4.) Residential development densities in the new hamlet are balanced with residential development densities in the surrounding [area] through the use of transfer of development rights, cluster development 


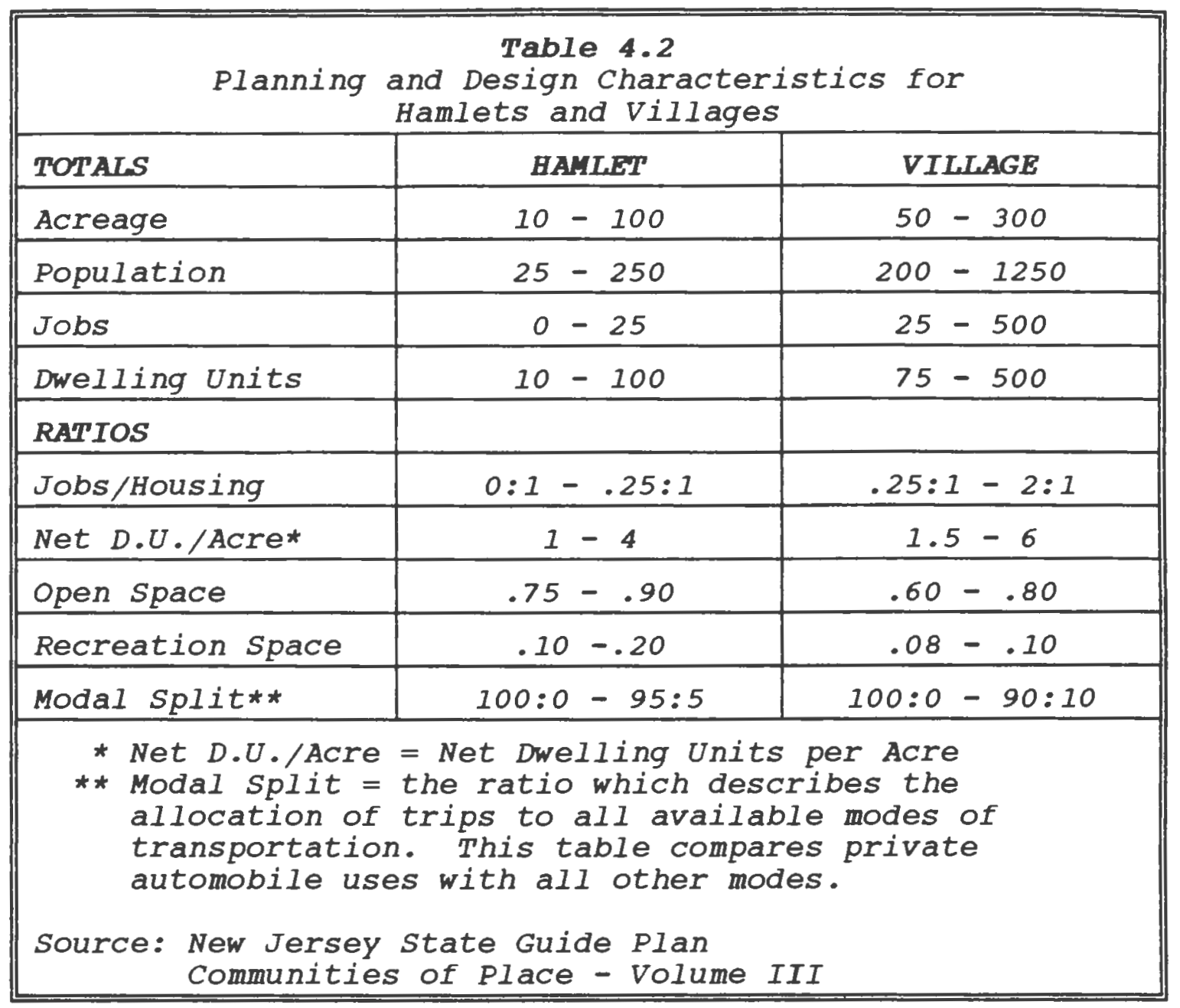




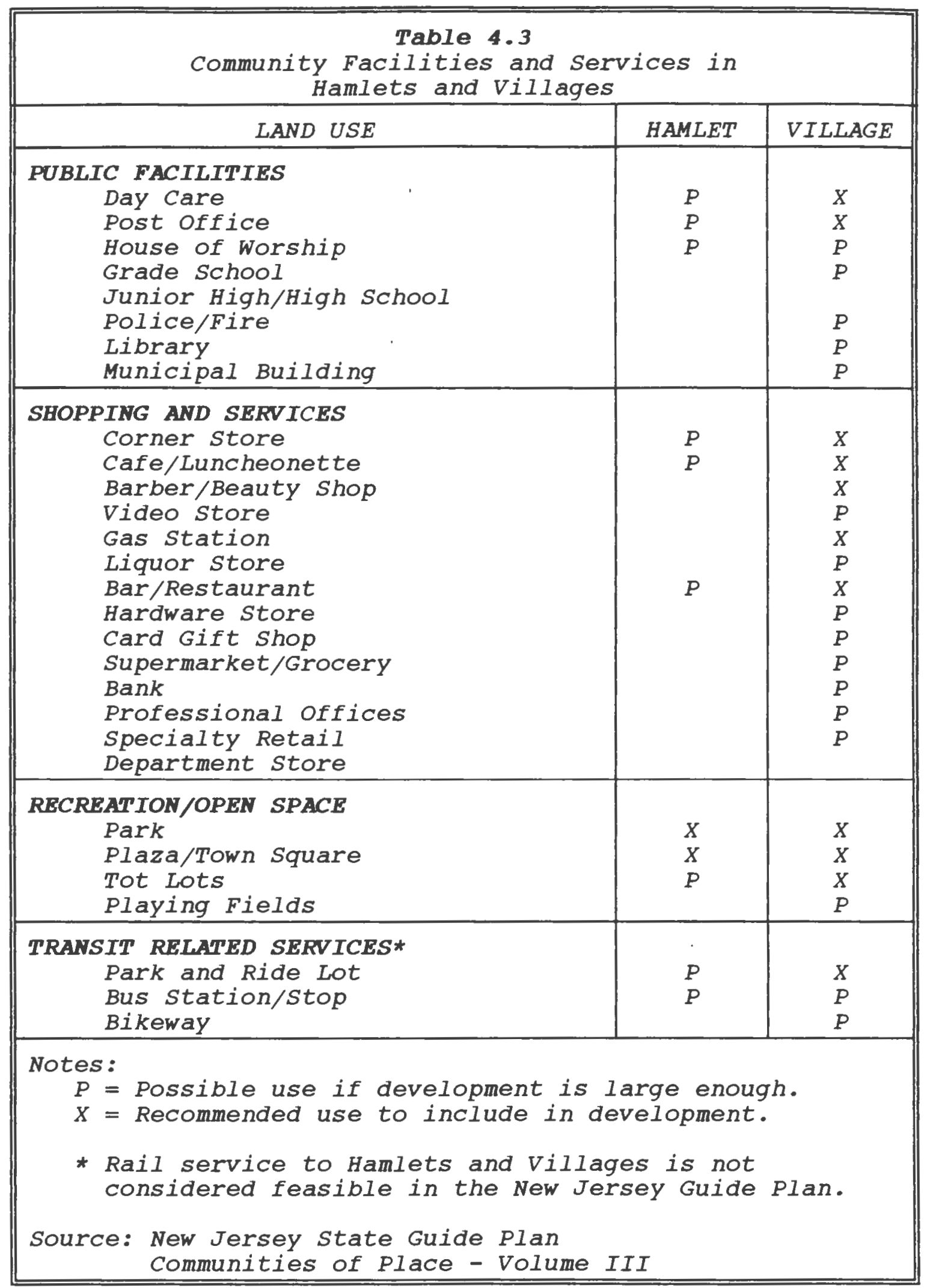


or other mechanisms... (Communities of Place V.III, p. 2-11)

The guide plan also outlines characteristics for the establishment of Villages:

1.) The new village area is generally a place within a municipality but which may also involve more than one municipality;

2.) The new village area may support a resident population corresponding to an average population density of 1000 or more persons per square mile but containing a resident population of less than 1250 persons;

3.) The new village area contains a mixture of residential and associated non residential uses as follows:

(a) development is generally limited to within $1 / 4$ mile of the village center;

(b) land uses are designed to support a pedestrian orientation and the rural setting in which the village is located; (Communities of Place V.III, p. 2-8)

other design guidelines include using open space ratios, jobs to housing ratios and the types of mixed uses that would be allowed in the hamlet and village. These guidelines are presented in Tables 4.2 and 4.3. The New Jersey Plan establishes the standards for what makes a hamlet and village that is transferable for uses in other communities.

\section{PEDESTRIAN POCKETS}

While the concept of neotraditional planning was developing on the east coast with architects and planners like Duany, Plater-Zyberk, and Nelessen, a group of architects and planners were formulating their own alternatives to sprawl pattern development on the west coast. Led by architect Peter 
Calthorpe, this group proposed a design concept with similarities to neotraditional planning; the pedestrian pocket. Like neotraditional planning the pedestrian pocket would contain compact residential neighborhoods that offered a mix of uses with civic spaces serving as focal points at the center of the development. It would also be surrounded by a greenbelt. The concept of the pedestrian pocket bears a striking resemblance to Clarence Perry's Neighborhood Unit.

\section{Design Criteria}

The size of a pedestrian pocket is to be no greater than one quarter mile radius from its center or a ten minute walk from center to edge. This translates into approximately 120 acres of land. A 60 acre model has been used by Calthorpe for demonstration purposes. (Figure 4.4) The development area is to be surrounded by a greenbelt area. Suggestions for protecting this land include agricultural zoning and transfer of development rights. Development areas within the greenbelt could hold up to 2000 units of housing and over 1,000,000 square feet of office space.

The design guidelines for buildings within the pocket are urban in character. Housing units will be limited to two story townhouse units in the neighborhoods and three story walkup apartments around the town center. The purpose of these housing types is to accommodate a population that is becoming more and more diverse in nature. According to 


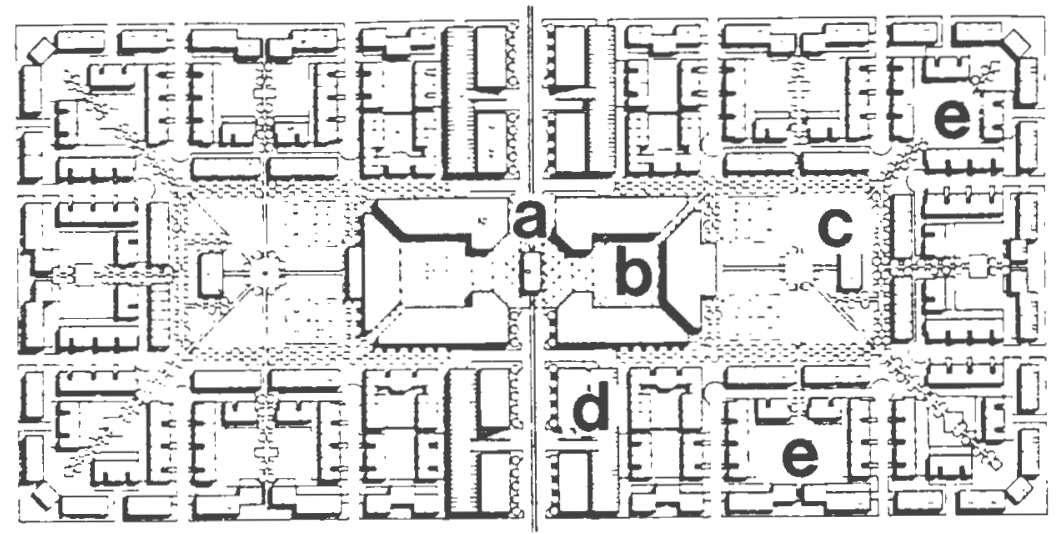

The model pedestrian pocket pictured above and below is approximately 60 acres in size. It illustrates the basic principles involved in planning and design. The light rail station (a) is the centerpiece of the design allowing fast and efficient travel between pockets. Surrounding the station are office uses (b) which can provide employment for pocket residents. Residential units (e) are located on the edge of the community and surround recreation and open space (c) Basketball and tennis courts are shown on the plan. Commercial uses with two level parking decks (d) lie adjacent to both the office space and the residential areas.

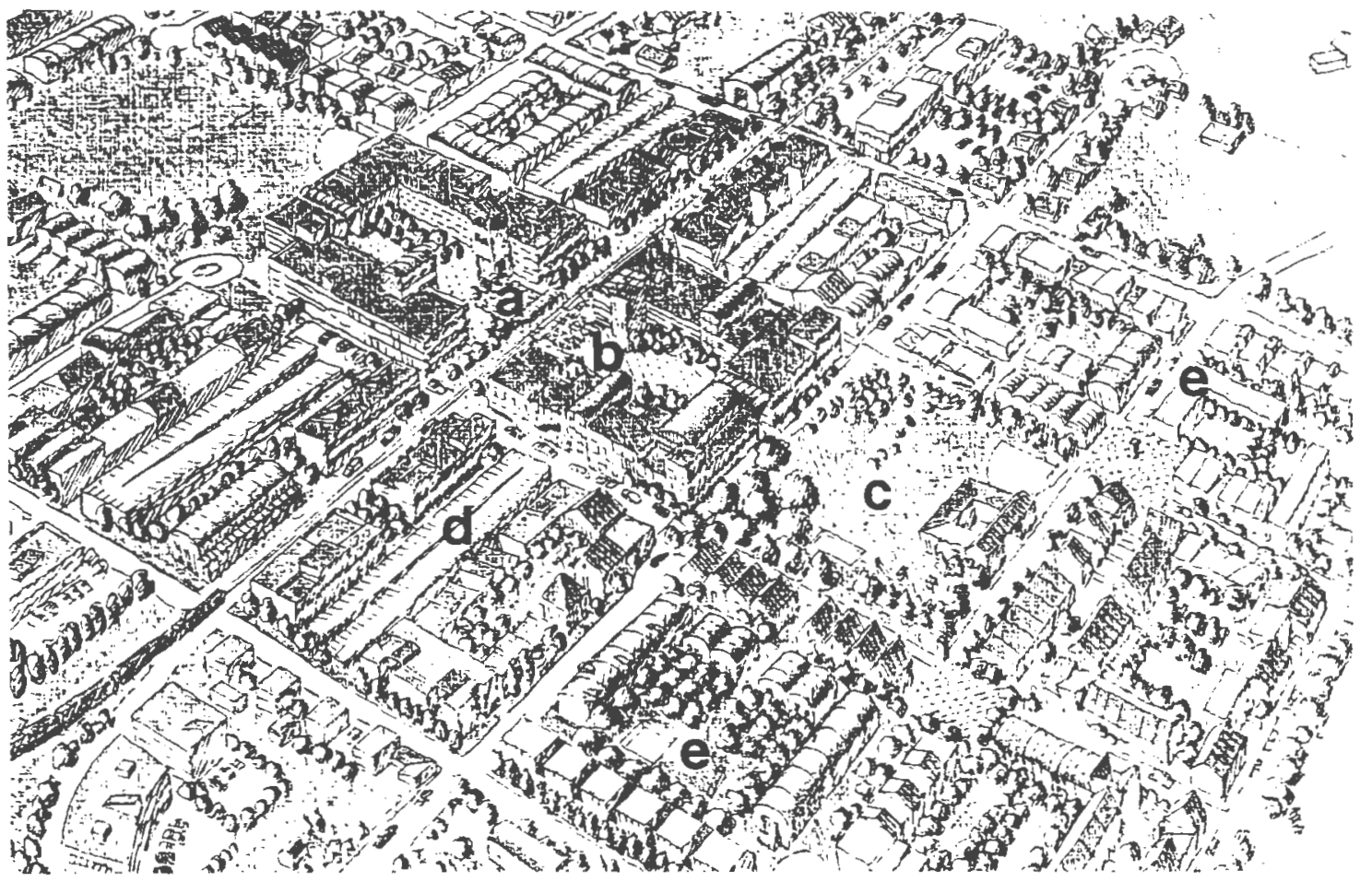

Source: PA Magazine, May 1989. 


\begin{tabular}{|c|c|}
\hline \multicolumn{2}{|c|}{$\begin{array}{c}\text { Table } 4.4 \\
\text { Typical Requirements for a } \\
\text { Pedestrian Pocket* }\end{array}$} \\
\hline LAND USE & $\begin{array}{c}\text { APPROX } \\
\text { SIZE }\end{array}$ \\
\hline LIGHT RAIL STATION & $10,000 \mathrm{sf}$ \\
\hline $\begin{array}{l}\text { BACK OFFICE USE } \\
\text { Typical floor plans of } 40,000 \\
\text { s.f of open office space }\end{array}$ & 500,000 sf \\
\hline $\begin{array}{l}\text { SERVICE OFFICE USE } \\
\text { Minimum of } 1000 \text { suites for } \\
\text { smaller tenants }\end{array}$ & $150,000 \mathrm{sf}$ \\
\hline $\begin{array}{l}\text { NEIGHBORHOOD RETAIL } \\
\text { Includes restaurants, markets } \\
\text { and shops that service local } \\
\text { population }\end{array}$ & $60,000 \mathrm{sf}$ \\
\hline $\begin{array}{l}\text { CIVIC FACILITIES } \\
\text { Police Station, Fire station, } \\
\text { Community Center and Town Hall, } \\
\text { Post office, library. }\end{array}$ & 25,000 sf \\
\hline DAY CARE FACILITIES & $2 \mathrm{e} 7,500 \mathrm{sf}$ \\
\hline $\begin{array}{l}\text { HOUSING UNITS } \\
\text { Single Family Detached } \\
\text { Townhouses/Duplexes } \\
\text { Apartments } \\
\text { Elderly Congregate Care }\end{array}$ & $\begin{array}{l}50 \text { units } \\
400 \text { units } \\
400 \text { units } \\
150 \text { units }\end{array}$ \\
\hline $\begin{array}{l}\text { COMMERCIAL PARKING } \\
\text { Computed at half the standard } \\
\text { requirement to discourage } \\
\text { automobile use }\end{array}$ & 1000 stalls \\
\hline $\begin{array}{c}\text { PARKS AND RECREATIONAL FACILITIES** } \\
\text { A central public area to be } \\
\text { defined by the specific use. }\end{array}$ & 12 Acres \\
\hline $\begin{array}{l}\text { Notes: } \\
\text { * The information was used in a de } \\
\text { March, } 1988 \text {. } \\
\text { * This does not include open areas } \\
\text { clustering of housing or commerc } \\
\text { Source: Pedestrian Pocket Handbook, }\end{array}$ & $\begin{array}{l}\text { workshop in } \\
\text { ion to the } \\
\text { ses. }\end{array}$ \\
\hline
\end{tabular}


Calthorpe, "our old suburbs were designed around a stereotypical household which is no longer prevalent". The growth of single occupant, single parent, elderly and small double income families need smaller more affordable units of housing.

The presence of such large quantities of commercial and office space is a simple one. The pedestrian pocket is meant to shift the workplace from the isolated industrial parks of the traditional suburbs to the center of the pedestrian pocket. The office space is designed to accommodate the suburban trend of back-office employers. Residents from the surrounding neighborhood could provide a good percentage of the labor force within easy walking distance to work.

Those who are not in living within the pedestrian pocket will still be able to travel back and forth to work because the centerpiece of the pedestrian pocket physically and socially will be the construction of a light rail system to service a series of pedestrian pockets. Light rail is the thread that links one pedestrian pocket with another and is necessary since one pocket would serve as a regional shopping center, another would act as a regional employment center, and another would act as regional transportation hub for the conventional suburbs. As a result of this regional scheme the best location for a series of pedestrian pockets would be along abandoned railroad rights of way. 
The final verdict on pedestrian pockets is still out. A pedestrian pocket is being constructed outside sacramento, California. The designers have met with some opposition to the concept and have had to make compromises in the design. As a result, there is a stricter segregation of uses and the street system is more automobile oriented than originally planned.

There is a catch-22 to the pedestrian pocket that even Calthorpe acknowledges; developers would not want to build without the light rail in place, yet government does not want to construct the light rail in without established pockets along the right of way. Calthorpe proposes that the initial right of way is established for van pools, buses and bicycles. Then, as the pockets mature, light rail can be added. This is a similar approach taken to the development lots in the TND.

The Pedestrian Pocket concept adds a new dimension to the combat against sprawl patterns of development. It is an attempt to link large scale employers with their employees by providing both housing and mass transit in a comprehensive manner. It provides an opportunity for local commercial uses in neighborhood settings while acknowledging that large scale commercial shopping centers have become a fact of life in the fringe community. 
RURAL LANDSCAPE PLANNING

The concept of Rural Landscape Planning offers alternatives intended to modify conventional zoning. It uses similar techniques found in many of the alternatives presented in this chapter and applies them to conventional zoning ordinances. The result is a conventional ordinance that has provisions designed to protect sensitive areas from sprawl pattern development.

The term "rural landscape planning" is associated with the work of The center for Rural Massachusetts and its Director for Planning and Research, Randall Arendt. The Center was created in 1985 by the Massachusetts Legislature. It goal was to seek solutions to preserving Massachusetts rural character. At that time, fringe communities in the Boston Metropolitan region were losing large acreages of what was once agricultural land to sprawl pattern development.

Conventional zoning in these communities followed the typical pattern of zoning existing with agricultural land for single family residential construction and commercial zones located along side major roads in the community. The future for these fringe communities was locked into the same pattern of development that was found further inside the core. Even developers who recognized the importance of preserving open space and the rural landscape were forced to design within conventional zoning guidelines. 
Arendt and the Center developed a series of alternatives that communities could use to shape the existing zoning ordinance into something that could preserve the character they wanted. These guidelines were published in Dealing with Change in the Connecticut River Valley: A Design Manual for Conservation and Development. The manual proposed specific tools for integrating new development into the fringe community by amending current zoning ordinances not eliminating them.

In rural landscape planning the conventional ordinance is modified by the use of a Farmland/Open space Conservation bylaw that requires developers to preserve a percentage of open space and to cluster housing units away from open farms and pasture land. Arendt also suggests clustering housing to mimic the look of the traditional farm (a main house with a barn and grouping of outbuildings). House lots would be reduced in size but no overall increase in density would be allowed. Restrictions would be placed on the resulting open space that would encourage continued or future agricultural use. Guidelines and site plan review would be required for all development in the area.

clustering would also be used in commercial zones to reduce the pattern of strip development. Commercial "nodes" would be placed at various locations along rural highways and would be buffered from the road using local vegetation. Buildings in commercial nodes would be allowed be no more than 
25 feet from the road and parking would be moved from the front of the lot to the sides and rear.

The focus of Rural Landscape Planning are small towns that do not have the financial, administrative, or political base for more comprehensive changes in the conventional zoning ordinance. It allows the modification, over time, of the conventional ordinance into something that approaches the complexity of performance zoning and the character of neotraditional or pedestrian pocket planning. Rural Landscape Planning has the potential to act as a bridge between the conventional zoning and the more "radical" planning alternatives presented.

\section{CONCLUSIONS}

All of the alternatives presented within this chapter offer real solutions to the problems created by conventional patterns of zoning. Communities must look at their own needs in deciding what, if any of these solutions, might work for them.

The similarities between neotraditional and pedestrian pocket approaches goes beyond the idea of accommodating the pedestrian, mixing uses and providing open space or a green belt. If it were just the features then the PUD would have been the answer. These alternatives are planned, subdivisions happen. There is a nierarchy and an order to the design of these that goes beyond the parts. 
Both of these alternatives present themselves in the traditional images of the city put forth by Kevin Lynch. The roadways are not "layed out". They are paths that terminate on focal points. The focal point become landmarks that establish a character within the community. A strong sense of center exists within these communities. The civic lots and the town common become nodes of social activity that residents can identify with. The variation in architecture and building type form distinct districts within the community that have identity. The greenbelt are more than open space. They are edges that separate the community and reinforce identity. There is also an additional element of identity imposed by the distinct sense of entry one feels when entering the pedestrian pocket or neotraditional community that conventional zoning does not seem to address.

Performance Zoning becomes the canvas on which the other alternatives can be painted. Calthorpe proposes pedestrian pockets spaced approximately one mile apart along a light rail line. The inflation of land prices along the line would certainly increase pressure for development and additional stops in between. Performance zoning standards could allow flexible development that would not diminish the environmental quality of the buffer zone. Land around a single TND would most certainly increase in value prompting further development. What is to prevent the repetitious pattern of 
TND's and New Villages from creating a different type of "mixed use sprawl" for the nineties.

Without some type of performance zoning standard in place around these compact mixed use zones, communities will resort to conventional zoning techniques in order to control development in the hinterlands. This will most likely take the form of low density five acre zoning. Instead of unspoiled tracts of land, low density sprawl patterns of development will be allowed to dominate the landscape. A need for even limited commercial services in this area will almost assuredly lead to limited commercial strip development. Performance zoning provides an alternative to communities that may want to institute the other alternatives but face opposition because of what they represent; a localized but more intense pattern of development than that currently being used. 


\section{INTRODUCTION}

One of the biggest problems facing the implementation of many of these new trends is resistance from the community and community leaders to abandon conventional zoning. There are several factors involved in this resistance. The most common has to do with the fear of changing the "status quo". The legality of conventional zoning has been upheld in courts and the basic concepts are well known to both local officials and developers. Residents know that if they move into a neighborhood zoned for residential use it will, with few exceptions, remain residential. While conventional zoning does have its problems it is safe.

When alternatives are presented, many communities look upon them with some mistrust. Performance zoning with all its density formulas and ratios can be confusing. The Pedestrian Pocket and Neotraditional models talk about grids and networks, and show buildings close to the street on small lots. Community leaders who have fought battles over minor adjustments in conventional zoning do not want to involve themselves with such radical ideas. All this makes any switch away from conventional zoning a hard and sometimes controversial one. 
Many communities have fought sprawl pattern development by altering conventional zoning. The conventional wisdom called for increasing lot sizes in residential zones. Larger lots means less people. Less people means less of an impact on services. The result is that most fringe communities use residential zones with two and five acre minimum lot sizes as a chief way to slow growth and preserve open space. Once a community has accepted this premise it is hard to convince them otherwise.

This chapter will focus on how community leaders and residents can be given a better understanding of what these new design trends are all about. The first section will focus on techniques that have been used by planners such as Anton Nelessen, Randall Arendt, and Andres Duany educating public officials and residents to the benefits that can be gained from adopting alternatives to conventional zoning. The second section will focus on how the proposed alternatives can be combined to present an option to conventional zoning techniques in a community. The community chosen for this application is Foster, Rhode Island. Foster was chosen because it is currently in the process of updating its comprehensive plan and residents have been reluctant to completely let go of conventional zoning. 
PRESENTING THE ALTERNATIVES

Telling a community that they have chosen the wrong direction with regards to development is not an easy thing to do. The pattern of development that is being referred to as inefficient, monotonous and detrimental to quality of life is, in most cases, the same pattern that many in the audience have grown up in and are most comfortable with. To convince a planning board or an audience full of concerned citizens to abandon conventional zoning after only one or two meetings would seem impossible. After all, the conventional zoning process went through months of hearings and even after adoption goes through a constant process of adjustment.

The proponents of the design alternatives presented in the previous chapter have recognized this resistance to change. They have come up with simple, yet innovative ways to educate and inform the public that alternatives to conventional zoning not only exist but offer a better solution to controlling growth and development in their community. All the presentation techniques used have the same fundamental principles for effecting change. First, they allow the audience to make up their own mind as to the pitfalls of conventional zoning by simply placing their alternative along side the current method of zoning. Second, they involve the use of visuals and graphics that most planners could easily adapt for use in their community. 
Randall Arendt and The Best Case/Worst Scenario

The use of best case/worst case scenario involves showing the public what an area of a community would look like if it were developed conventionally compared with what it could look like if alternative techniques were used. While this is not a new concept, Randall Arendt and the center for Rural Massachusetts used it most effectively in changes in the Connecticut River Valley. The pictures of conventional zoning side by side with the Center's alternatives for growth are startling. In the word of one reviewer, "Conventional development covers fields with a Euclidian pox of house lots and streets". (Macleish: 1990: 52) The alternatives with clustered designs and open landscapes clearly reflects a more attractive option.

Arendt has incorporated this technique into a lecture that he has given in communities across New England. The two hour lecture also includes a presentation of typical New England character represented in small towns and villages nestled into hillsides with village greens and a section comparing good clustered development and bad conventional development. The use of these techniques has proven successful for both Arendt and the Center. Several communities have adopted the open space provisions recommended by the Center after having Arendt address their community.

The Newport Collaborative Architects \& Planners, consultants for the Town of Foster used the best case/worst 
case scenario during the Town's comprehensive plan update. Plans for development on an historical farm site were drawn up according to the Town's conventional zoning ordinance and subdivision regulations. An alternate proposal showing a cluster design following rural landscape planning guidelines was also drawn up. When placed side by side in front of the Comprehensive Plan Advisory Committee, the members overwhelmingly approved of the cluster development scheme even though previous discussions about cluster development scenarios had not been met enthusiastically.

\section{Anton Nelessen and Community Preference}

The idea of "community preference" lies at the heart of Anton Nelessen's two step approach to Village and Hamlet Design. His reasoning is simple; even though people live in a conventionally zoned world, they prefer a world made up of small towns and villages. Once people realize that conventional zoning is not giving them what they really want, the acceptance of alternatives is relatively easy.

The techniques used by Nelessen involve an interactive exchange with the audience. The first part of the presentation involves the use of slides; 250 of them. Audience members are given forms and asked to rate the slides as they appear on the screen. The scoring ranges from +10 for extremely pleasant views to a -10 for the extremely unpleasant views. The subjects of the slides include standard 
subdivisions, strip shopping areas and sprawl patterns of development and traditional small centers, village green and small scale patterns of development.

The results of the slide show are always the same. The views that represent neotraditional planning usually score on the plus side. Those slides that represent conventional zoning score on the low side. Nelessen probes the audience to determine why they liked the things they did. The point is made. The audience comes to their own conclusions on what they prefer and it is not conventional zoning.

The second part of the presentation is a hands on exercise in planning. Armed with balsa wood models and magic markers, the audience is asked to design a Hamlet based on the things they preferred in the first part of the presentation. Most of the finished designs are small, compact, with greens and open space. If several groups are involved, the hamlets are pieced together to form villages. There is a sense of accomplishment and pride in the finished product.

The next thing Nelessen does is shatter the illusion. The villages people are so proud of are compared with the community's current zoning and subdivision regulations. The small lots, narrow streets and $\mathrm{mix}$ of uses encouraged by Nelessen and preferred by the participants are illegal. The effect can be dramatic, especially if members of a planning board happen to be participants. Again, the point is made. 
There is something wrong with conventional zoning because it does not allow what people prefer.

\section{Andres Duany and the Charrette Process}

The firm of Duany/Plater-zyberk use more traditional design and presentation principles in pursuing the shift away from conventional zoning. This is based on a clientprofessional relationship, with the client wishing to place a TND on a specific site within a community. In most cases the community has never heard of a TND and current zoning and subdivision regulations do not allow anything like it. Faced the problem of selling not only the design but the design concept, Duany has established a system which attempts to solve both problems.

The term "charrette" is used by architects and planners and represents a concentrated effort to solve a problem. In a charrette all other things are pushed aside except for the problem at hand. Duany uses this concept to develop both a TND design and ordinance for the community. Duany assembles a team of planners, architects, engineers to gather as much data as possible on the community. The team travels to the site and over the course of one week prepares a master plan that includes the site design and an ordinance package to manage future growth. Further refinement of the process has produced a model ordinance that allows for communities to 
pursue neotraditional development without fist finding a client.

The charrette process aids the overall planning process by bringing the entire design team in contact with the site and the community. The team is focused on the solving the problem at hand and is not distracted. By presenting an ordinance and design guidelines in addition to a site plan, the design team is showing that they are committed to helping create overall change in the community long after their project is over. If used correctly, the charrette process goes to the heart of the planning process by taking into account a need for integrating a large scale process into the community fabric.

\section{THE ALTERNATIVES APPLIED}

This section will focus on the application of alternatives to conventional zoning presented in the previous chapter. The process need not be complex. It involves determining the existing conditions of the community and based on their goals and objectives use the alternatives to develop an alternate scenario. This section will examine Foster, Rhode Island's present method of zoning and outline how alternative methods can be introduced into the community. 


\section{Community Profile}

The town of Foster lies due west of Providence, Rhode Island along the state's western border. Foster is approximately 52 square miles and was incorporated as a town in 1781. For most of its 200 year history, Foster has been a community containing mostly agricultural use with pockets of commercial and industrial development centered around small villages and hamlets. During the last 50 years, the town has seen modest growth due to suburbanization in the Providence Metropolitan Area.

Today, Foster is still a rural community with almost $70 \%$ of its total acreage either vacant or not developed to what could be allowed through current zoning. (TNC: 1990: 2) The town's topography is fairly steep for Rhode Island standards with rolling terrain and several valleys. Rocky soil conditions exist in most parts of Foster and bedrock outcroppings can be seen in many areas. Its soil conditions are considered poor for intense development. Although it is considered an "agricultural" community, only 2\% (TNC: 1990: 4) of the land is used solely for agricultural purposes yet many large residential tracts appear to have secondary agricultural use.

Foster, like many towns in the northwestern part of the state remains fairly isolated due partly to the fact that they are not along any major transportation corridors. State Route 6, a four lane road, is the only major highway through town 
and at one time it was the main linkage between Hartford and Providence. Today it is only a secondary route through the state. Most other roads in Foster are two lane local roads and several of the roads appearing on town maps are not paved. There is no railroad or public transportation serving Foster. Foster is a small community with a population of only 4316. (U.S. Census: 1990) The Town of Foster has been growing at fairly steady rate of approximately $28 \%$ per decade since 1940. According to the 1980 census, the median age of Foster residents was 30.5 years, with $59.5 \%$ of the population between the ages of 18-64 (labor force) and $31.5 \%$ of the population under 18 .

A survey distributed to town residents as part of the 1990 Comprehensive Plan update revealed attitudes of the residents in the community. Two thirds of the respondents moved to Foster because of its rural character and almost one third (31\%) said they would leave Foster if it became too suburban. Most of those responding (72.1\%) see Foster as a place to settle down and expect to stay in town for more than 15 years. Almost all the respondents (93.1\%) want to see town leaders working to maintain the town's rural character. This includes keeping many of Foster's dirt roads - 63\% agree they should be kept as they are. overall, almost all the respondents (93\%) rated quality of life in Foster as either good or very good. 
Zoning and Land Use

The Town of Foster currently categorizes land use into six categories. An Agricultural/Residential (AR) is a very low density residential use zone. A Highway Commercial (H) zone is meant to carry the bulk of the town's commercial development. A Neighborhood Commercial (NC) zor.e is meant to hold low intensity commercial uses that cater primarily to residents. A Manufacturing Industry (MI) zone has been set aside in the northern part of town. Two floating zones, a Municipal (M) and a Residential zone for senior citizens homes (R-SC) have been created to allow specialty functions.

\section{Residential Uses}

Residential development in Foster is allowed by right in only one of Foster's land use zones; the AgriculturalResidential (AR) Zone. This zone covers well over $90 \%$ of the Town and according to the Town's Zoning Ordinance is meant to "help preserve the rural character of the town" and "protect land now used for agriculture and forestry from haphazard encroachment". Whether or not the AR Zones accomplish rural preservation is of concern.

Zoning regulations for the Town require at least 4.6 acres of land on which to build. The "5 acre" lot as this is called is and will continue to be the most predominant use of land allowed by current zoning ordinances. A minimum of 300 feet of frontage is required on these lots and most of the new 


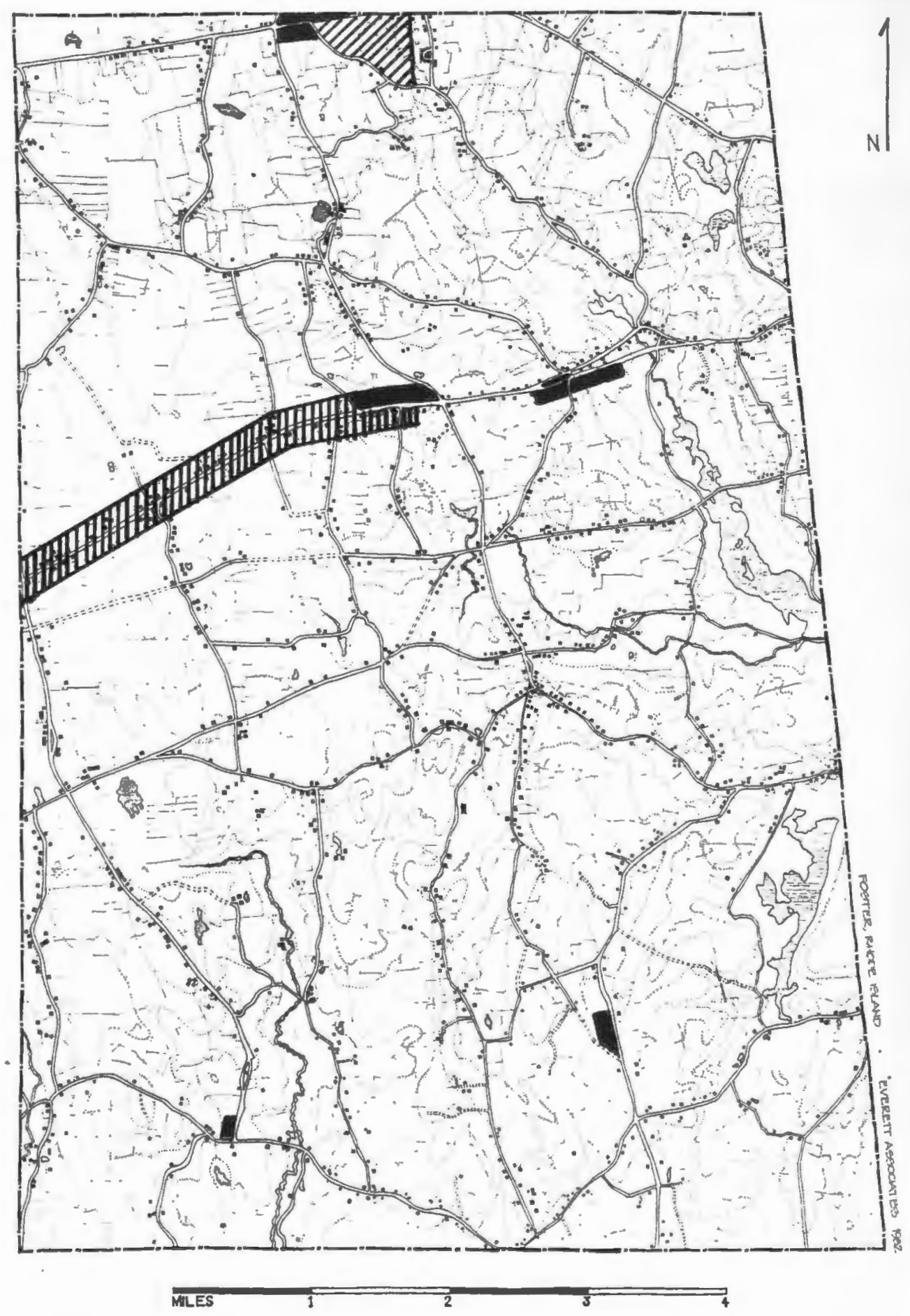

Figure 4.1 - Foster, Rhode Island Conventional zoning Source: Planning Department, Town of Foster

ARGRICULTURAL/RESTDENTIAL (AR)

HIGHWAY COMMERCIAL (HC)

NEIGHBORHOOD COMMERCIAL (NC)

MANUFACTURING INDUSTRY (MI)

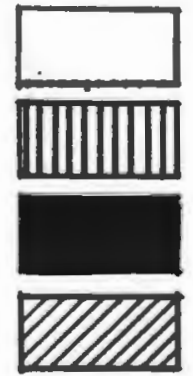


"5 acre" lots created in the last 10 years do not exceed this minimum. This results in a pattern of relatively long and thin lots facing the roadways sometimes referred to as "piano keys" because of the way they appear on a map. When combined with a shallow 35 foot setback, these lots give the appearance that the town is more developed than it actually is. Frontage and setback requirements cause development patterns that place the houses at approximately $250^{\prime}$ intervals along the roads giving the town a suburban look and character.

Commercial Uses

The bulk of the commercial property in the Town of Foster is located along Route 6 . Most of the properties are single use retail establishments that serve local residents and traffic traveling along the Route 6 corridor. Approximately half of the existing commercial properties listed in the records of the Foster Tax Assessor do not appear to be located in existing areas zoned commercial.

There are two zones that have been created to allow for commercial development. The Highway Commercial (H) Zone is located along the Route 6 corridor. Foster is lucky and has been spared the intensive commercial "strip" development that this type of zoning has brought to other communities. The current HC zone if developed would allow strip malls, fast food restaurants and office buildings to be constructed on for several miles along both sides of Route 6 . 
A Neighborhood Commercial (NC) Zone was created in several areas of the Town "to provide convenient local shopping services and to promote public safety for both pedestrian and vehicular traffic". As previously stated, it appears that the local shopping services remain located along the Route 6 corridor with little signs of moving. The existing NC zones are not large enough to support the mix of uses needed to create a "neighborhood commercial" area and the Zoning Ordinance does not allow the types of development that have traditionally olended pedestrian and vehicular traffic. Limited commercial use is allowed in the AR Zone. Home occupations not using more than 200 sq. ft. in a residential structure are allowed by right. Fruit stands and grocery stores less than $1000 \mathrm{sq}$. ft. in size are allowed to be built on a residential property by permission of the Zoning Board.

Industrial Uses

Only three properties in Foster are listed as being used for industrial purposes. (TNC: 1990) Foster has set aside 155 acres of land as a Manufacturing-Industrial (MI) Zone and the Turnquist property takes up almost half of it. Many of the uses permitted in an MI Zone are also allowed either by right or special exception in Foster's other zones. 


\section{Agricultural Uses}

Only 2.1\% (approximately 700 acres) of land in Foster is used purely for agricultural purposes. (TNC: 1990) There are two large parcels of land in the northern end of town and several smaller parcels in the vicinity of Cucumber Hill Road and North Road. The average parcel size for agricultural land was over 50 acres. Large parcels of this size are needed to sustain viable agricultural uses. As previously stated several large lot residential properties appear to be supporting secondary agricultural use.

\section{Other Uses}

Institutional land is made up of properties that are used by tax exempt agencies in the town. This includes non profit and charitable organizations and churches. It also includes Town and state owned properties. Institutional land in Foster is scattered throughout the town. Many of the town owned properties are located in the vicinity of Foster Center. Most of the church owned properties have historic significance and include several historic cemeteries.

Foster does have a zone limited to municipal uses; the Municipal (M) Zone. Like the R-SC Zone, land use in this zone is severely limited in use. Although the Zoning ordinance says it encompasses land in and around Foster center this zone does not appear on the official zoning Map. 
The large tracts of vacant land and the rural character of Foster provide its residents with ample opportunity for recreational use. However, this land is not set aside for recreational purposes and can be developed at any time. Only about $1 \%$ of land in Foster is being used for recreational purposes. (TNC: 1990) The town has one recreational facility in the south end of town and open space behind the Isaac Paine School. Open recreational land which includes playgrounds and parks is allowed by right in all of Foster's mapped zones. This gives the town the opportunity to create recreational areas in all areas of town.

There is more vacant land in the Town of Foster than there is used by any other land use category with the exception of residential land greater than 9.2 acres. Approximately $35 \%$ of the total land comprising 11,550 acres is vacant.(TNC: 1990) Almost all of this vacant land sits in the Agriculture-Residential Zone and will surely be developed into "5 acre" lots. A large number of vacant lots have little or no frontage. The only way some of these can be developed is through the use of new roads conforming to subdivision regulations. These roads will become the responsibility of the town upon completion.

summary

The Town of Foster is living on "borrowed views". Approximately $70 \%$ of the total acreage of the Town of Foster 
remains either vacant or underdeveloped. That is to say that much of Foster's rural and agricultural landscape can be subdivided for residential use at any time. Current Setback and lot frontage requirements in Foster's Zoning ordinance are creating a homogeneity of land use that mimics the suburban sprawl conditions seen in more developed communities. Conventional zoning in Foster is not doing what it is supposed to do. Even though the minimum lot size makes the AR zone about as low density as can be, sprawl pattern development is still occurring. The existing Highway Commercial (H) Zone is not in keeping with Foster's rural character and the Neighborhood Commercial zones are not promoting the type of growth that they were meant to.

\section{Current Land Use Policies}

Current comprehensive planning in the Town of Foster has raised many of the problems of conventional zoning as issues for discussion in the land use section of the comprehensive plan. The draft goals include a statement on promoting land use patterns that:
"reflect and respect the Town's natural resources, wildife habitat, and rural density traditions, reinforce overall Town identity and provide generous amounts of open space between village centers" (TNC: 1991)

While policies formulated based on this goal include provisions for performance zoning as well as village and Hamlet zoning there are also policies that seek to maintain 
the current status of conventional zoning with the addition of standards for cluster development and overlay zones on the existing conventional pattern.

It is this modification of the existing pattern that forms the bridge to a more comprehensive alternative. The use of cluster zoning in Foster will most likely follow guidelines established by Randall Arendt for rural land planning. A percentage of open space (50\%) will be required. Site plan review of cluster developments will be instituted. Sensitive environmental areas on the site will be protected.

The requirements for development in the overlay zones will institute performance standards on the conventional zoning district. Performance standards are basically the same criteria that forms the basis for performance zoning. Steep slopes, wetlands, high water tables and sensitive ecological habitats are all marked as possible performance standards attached to the proposed Farmland - Rural Conservation (F-RC) Overlay zone proposed for Foster. This overlay zone is in essence a performance district. Foster is a community with severe constraints in many categories. As a result, the F-RC overlay zone will cover a large majority of the Town.

With so much land coming under site plan review it seems logical that the performance zoning should become the standard for controlling development not the exception. It will place all land in performance districts that the Town can use to control settlement patterns. It will establish a set of 
standards for site plan review that will apply to all property. It can help to rectify the level of inaccuracy that always seems to appear on the constraints maps.

\section{Alternative Land Use Policies}

The alternatives presented in the chapter Four can be used to form a new direction for growth in the Town of Foster. Performance zoning can be used to establish districts that protect the rural character that Foster residents clearly want to maintain. Using Kendig's standards, the performance districts that would most likely transfer directly to Foster are the Rural District, the Agricultural District, and an Estate District.

The Town would embark on this rezoning by determining what land it wants to preserve. The preparation for the F-RC overlay zone has already accomplished this. Land in several categories was combined to produce a map showing farmland, scenic areas and wetlands/hydric soils.

Land currently marked as having a high potential for agriculture could be zoned using agricultural district standards. The most likely area is the southwestern corner of Foster. This district has a high open space ratio (.90) allowing only $10 \%$ of the site to be developed. The remaining land would remain as open farmland. This type of district would prevent farmland from being subdivided one small parcel at a time until the farmland was whittled away to nothing. 


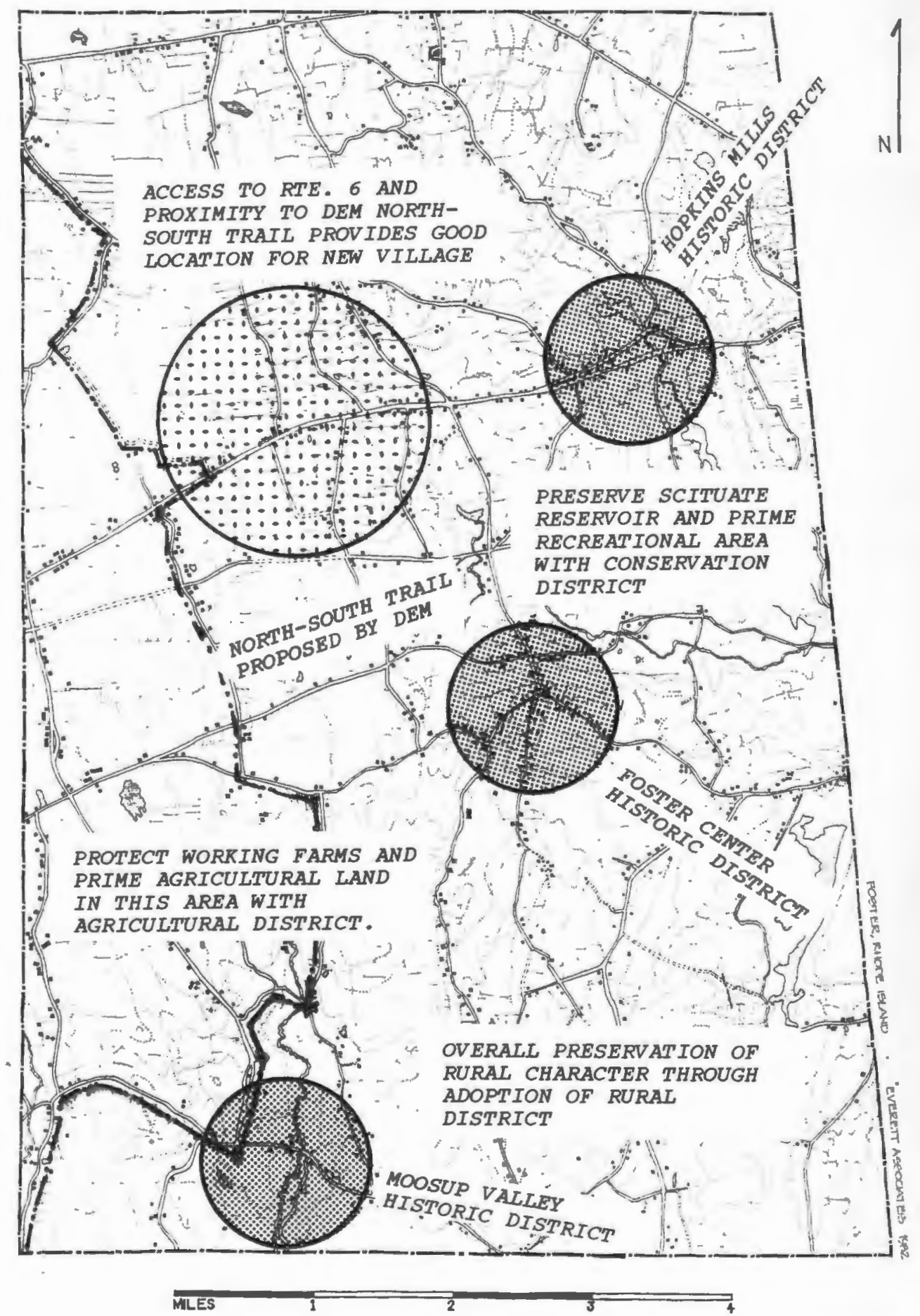

Figure 4.2 - Foster, Rhode Island Performance Zoning

The map of Foster above shows prominent features that should be taken into account when determining Performance zoning districts. Further analysis should be undertaken to determine the exact location of the district boundaries. Planning consultants working with the community have determined the boundaries of a Farmland-Rural Conservation overlay district that can be used to preparing boundaries for the conservation and Agricultural Districts. Maps showing hydric soils and wetlands can be used to determine the feasibility of a New village in the target area. Existing boundaries can be used to create the Historic Districts. 
Land marked as being of scenic or recreational potential could be marked for use in a conservation district. This is also a district with high open space ratios (.7 or more). Its primary function is to protect view sheds and scenic corridors by altering the resource restrictions of what is to be protected (ie. slopes, forests, lake shore). Sections on the eastern side of Foster in near the Scituate Reservoir could be protected with this type of District.

Since Foster wants to keep gross densities low and limit services to the community, most of the remaining area in the community should be developed as a rural district. Like the other districts it requires a high open space ratios. Areas with hydric soils and wetlands need not be placed in special zones. Resource restrictions could be established that protect these areas from intense development.

The question where to channel commercial and light manufacturing is more complex. Most of the other districts Kendig outlines require town sewers and water which Foster does not plan to install in the near future. Kendig does not recommend establishing development districts without the infrastructure planned or in place. However, this does not mean that the small commercial and manufacturing uses that Foster residents want cannot be accommodated. There are options.

The first is to simply allow the development of commercial uses in the rural districts. Performance zoning 
has provisions for restricting uses. The Town utilizes use requirements in the current conventional zoning ordinance. Commercial uses in Performance zoning also control the size of development with the use of a Floor Area Ratio. This limits the size of a commercial or manufacturing use to certain percentage of the gross site area. Where the building would be part of a larger development, the lot the building sits on would be used in stead of the gross site area. This technique is also used in many conventional zoning ordinances.

The second option is to use the requirements for village and hamlet zoning outlined in chapter 4. A standard size for either a hamlet or village would be decided on by the town.1 The town would then also have to determine the best location for this type of development. One posible location would be along the north or south side of the current Route six Corridor. This would also be close to the a new North-South Trail proposed by The Department of Environmental Management. A village near this trail could offer convenience services to trail users as well as residents.

Hamlets and villages would be allowed in the Rural District provided certain minimum lot size criteria were established. There is discussion for allowing commercial uses in the current RR5 zone with performance standards attached. A second approach would be to modify Kendig's concept of a

2. See Chapter Four, Village and Hamlet Zoning for design criteria. 
Holding zone to allow this type of development. Originally the holding zone was to be placed on unincorporated land that was slated for future development. The district would be allowed to develop at low density until such time that a proposal for a village concept is proposed. This concept would be similar to designating a landing zone in Transfer of Development Rights. This is more complicated but would allow the community to determine where to accommodate growth.

Additional zones would be necessary to protect Foster's existing pattern of Hamlets. While conventional zoning establishes historic districts as overlay zones over conventional zoning districts, Performance Zoning establishes the historic district as a separate and unique entity. It uses open space guidelines to create buffer zones around the edges of the historic district protecting its integrity. Compliance to architectural guidelines within the district would be the same as in conventional zoning.

\section{Summary}

This section has shown that the move from conventional to performance zoning would not be too complex. In fact, the Town could phase in performance zoning over time. The historic overlay districts for the Hamlets are already in place. The establishment of the F-RC overlay district with performance standards is being proposed. Both these districts are will sit on top of conventional zoning. It would be very 
easy for the town to fill in the missing pieces with a Rural District. Then it could just pull the conventional zoning districts out from under the performance zoning districts and let the performance districts fall into place.

\section{CONCLUSIONS}

This chapter has shown that the design alternatives presented in this project are viable alternatives to conventional zoning. In fact, it appears that more and more communities are moving toward the adoption of performance standards on top of conventional zoning as way of controlling growth. The reluctance to drop conventional zoning stems not from the desire to keep this type of land use control, but on the misconception of the alternatives being presented. It appears from the first section of this chapter that when confronted with the facts, communities will see the fallacy of their present system and take steps to move toward these new techniques in zoning. 
- 1988. Princeton Forrestal Village. Project Reference File. Washington, D.C.: Urban Land Institute.

- 1986. Seaside, Walton Co. Florida. Project Reference File. Washington, D.C.: Urban Land Institute.

- 1990. Architecture Vs. Planning Collision and Collaboration in the design of American Cities. Center, Volume No. 6. New York: Rizzoli.

- 1989. Prince Charles and The Architectural Debate. Architectural Design, Profile No. 79. New York.: St. Martin's Press.

- 1990. Special Issue: Architects and the Environment. Progressive Architecture, March.

American Society of Civil Engineers. 1939. Land Subdivision. New York.

Arendt, Randell Et.al. 1989. Dealing with Change in the Connecticut River Valley: a Design Manual for Conservation and Development. Lincoln Institute of Land Policy.

Baldassane, Mark. 1986. Trouble in Paradise: The Suburban Transformation in America. New York: Columbia University Press.

Banerjee, Tridib and Southworth, Michael eds. 1990. City Sense and City Design: Writings and Projects of Kevin Lynch. Cambridge, MA.: MIT Press.

Boles, Doralice. 1989. Reordering the Suburbs. Progressive Architecture, May: 78-91.

Bressi, Todd. 1990. Cities to Walk in. Metropolis, March: 5458 .

Brown, Denise Scott. 1990. Urban Concepts. Architectural Design, Profile No. 83. New York: St. Martins Press.

Calthorpe, Peter and Van der Ryn, Sym. 1986. Sustainable Communities. San Francisco, CA.: Sierra Club Books.

Chapin, Stuart and Kaiser, Edward. Urban Land Use Planning. Chicago, IL.: University of Illinois Press. 
Curry, Christopher. 1989. Impact of Four industrial Developments on a Rural Community: The Case of Lakeville, Massachusetts. University of Rhode Island.

Dunlop, Beth. 1990. City Edge. Architecture Magazine, April: $75-83$.

Duany, Andres. 1990. Suburban Sprawl or Livable Neighborhoods. Symposium on Neotraditional Town Planning, Washington, D.C.:Planners Training Service.

Fishman, Robert. 1987. Bourgeois Utopias: The Rise and Fall of Suburbs. New York: Basic Books Inc.

Frank, James and Rhodes, Robert Eds. 1987. Development Exactions. Washington, D.C.: APA Planners Press.

Gallion, A. and Eisner, S. 1986. The Urban Pattern: City Planning and Design. New York: Von Nostrand Reinhold.

Gottdeiner, Mark. 1977. Planned Sprawl: Private and Public Interests in the Suburbs. London: Sage Publications.

Hester, Randolph Jr.. 1975. Neighborhood Space. Stroudsburg PA.: Dowder Hutchinson \& Ross.

Johnson, Tom. 1990. Return to Main St. Home Magazine, January.

Kelbaugh, ed. The Pedestrian Pocket Book: A New Suburban Design Strategy. New York: Princeton Architectural Press.

Kendig, Lane. 1980. Performance Zoning. Washington, D.C.:APA Planners Press

Kostof, Spiro. 1987. America By Design. New York. Oxford University Press.

Lochmoeller, Donald Et.al. 1977. Industrial Development Handbook. Washington D.C.: Urban Land Institute.

Macleish, william. 1990. Battle For the Countryside. New England Monthly, September: 52-59.

Moore, Colleen and siskin Cheryl. 1985. PUDs in Practice. Washington. D.C.: Urban Land Institute.

Nelesson, Anton. 1989. Hamlets and Villages in the Neotraditional Form. New Jersey Environmental Commission.

Nolan, John. 1980. Affordable Housing: Public and Private Partnerships for Constructing Middle and Moderate Income Housing. White Plains, NY.: Center For Community Development and Preservation. 
O'Mara, Paul. 1982. Office Development Handbook. Washington, D.C.: Urban Land Institute.

Patton, Phil. 1991. In Seaside, Florida, the forward thing is to look back. Smithsonian, March: 82-93.

Pierson, William H. Jr. 1980. American Buildings and Their Architects. New York. Anchor Books.

Porter, Douglas R. 1986. Covenants and zoning For Research/Business Parks. Washington, D.C.: Urban Land Institute.

Robinette, Gary. 1984. How to Make Cities Livable. New York: Van Nostrand Reinhold Co.

So, Frank and Hand, Irving and McDowell Bruce, eds. 1986. The Practice of state and Regional Planning. Washington D.C.:APA Planners Press.

So, Frank and Getzels, Judith, eds. 1988. The Practice of Local Government Planning. Washington, D.C.: APA The Planners Press.

The Newport Collaborative Architects (TNC). 1991. Foster Comprehensive Plan: Draft Goals and Policies

Venturi, Robert. 1962. Complexity and contradiction in Architecture. New York: Museum of Modern Art 